\title{
Combating the dark side: managing performance reinvigoration of long-term relationships
}

Citation for published version (APA):

Jüliger, M. (2013). Combating the dark side: managing performance reinvigoration of long-term relationships. [Doctoral Thesis, Maastricht University]. Maastricht University. https://doi.org/10.26481/dis.20131011mj

Document status and date:

Published: 01/01/2013

DOI:

$10.26481 /$ dis.20131011mj

Document Version:

Publisher's PDF, also known as Version of record

\section{Please check the document version of this publication:}

- A submitted manuscript is the version of the article upon submission and before peer-review. There can be important differences between the submitted version and the official published version of record. People interested in the research are advised to contact the author for the final version of the publication, or visit the DOI to the publisher's website.

- The final author version and the galley proof are versions of the publication after peer review.

- The final published version features the final layout of the paper including the volume, issue and page numbers.

Link to publication

\footnotetext{
General rights rights.

- You may freely distribute the URL identifying the publication in the public portal. please follow below link for the End User Agreement:

www.umlib.nl/taverne-license

Take down policy

If you believe that this document breaches copyright please contact us at:

repository@maastrichtuniversity.nl

providing details and we will investigate your claim.
}

Copyright and moral rights for the publications made accessible in the public portal are retained by the authors and/or other copyright owners and it is a condition of accessing publications that users recognise and abide by the legal requirements associated with these

- Users may download and print one copy of any publication from the public portal for the purpose of private study or research.

- You may not further distribute the material or use it for any profit-making activity or commercial gain

If the publication is distributed under the terms of Article $25 \mathrm{fa}$ of the Dutch Copyright Act, indicated by the "Taverne" license above, 


\section{Combating the Dark Side:}

Managing Performance Reinvigoration of Long-Term Relationships

(C) 2013 by Matthias Jüliger

All rights reserved. No part of this publication may be reprinted or utilized in any form or by any electronic, mechanical or other means, no known, or hereafter invented, including photocopying and recording, or in any information storage or retrieval system, without written permission of the copyright owner.

Cover Design: 6grad51 Design.

Printed by: Druckerei Braun, Lindlar, Germany. 


\section{Combating the Dark Side:}

Managing Performance Reinvigoration of Long-Term Relationships

\section{PROEFSCHRIFT}

ter verkrijging van de graad van doctor aan de Universiteit Maastricht op gezag van de Rector

Magnificus, Prof. dr. L. L. G. Soete volgens het besluit van het College van Decanen, in het openbaar te verdedigen

op vrijdag 11 oktober 2013 om 10.00 uur door

Matthias Jüliger 


\section{Promotores}

Prof. dr. Ko de Ruyter

Prof. dr. Martin Wetzels

\section{Beoordelingscommissie}

Prof. dr. Jos Lemmink (voorzitter)

Prof. dr. Annouk Lievens, Universiteit Antwerpen

Prof. dr. Janjaap Semeijn 



\section{Acknowledgements}

My dissertation highlights the importance of (business) relationships. In this vein, the dissertation itself is to a large extent the result of many professional and private relationships that greatly contributed to its finalization.

Primarily, I am indebted to my promoters Prof. dr. Martin Wetzels and Prof. dr. Ko de Ruyter. You offered me the PhD position and I have greatly benefited from working with you. Martin, thanks for your methodological advice and your inspirational mentoring throughout the four-year process. It was also pleasure to teach your course and great to visit many conferences together. Ko, thanks for your 5000 meter altitude view on the dissertation to build a contribution. In the end it was a tough process of productive destruction through which both of you have guided me with encouragement and enthusiasm. Thanks for your supervision and infinite support.

Furthermore, I am grateful to Prof dr. Jos Lemmink, Prof. dr. Annouk Lievens, and Prof. dr. Janjaap Semeijn. Thanks for your efforts during the review process of the dissertation and your constructive feedback. Likewise, I would like to thank Prof. dr. Rajiv Dant from the University of Oklahoma for supporting my research on the dark side and for inviting me over to Oklahoma.

I am also thankful to all members of the Marketing and SCM department. In particular, thank you Pascalle and Eefje for managing most administrative issues related to my PhD. You made my life easier. Thanks also go to Anne, Kelly, and Dhruv for your input on setting up robust experiments. Lieven and Frank, you guys were a great help in facilitating the data collection among purchasing professionals. Jan, we got on the rollercoaster together: quant courses, joint experiments, office mates for four years. While the ride was sometimes fast and rough, a sense of irony was always on our side ("verkalkert"). Thanks also go to my 
other F1.04 office mates Nina and Jan P. Aaron, thank you for revising my chapters, for good times at the OU big-boys gym, at Cattlemen's and the Dollar Theater, in Chicago, and in Maastricht. I also remember great trips with the $\mathrm{PhD}$ community to the Ardennes, Bruges, Arcen, Prague, Budapest etc. It was my pleasure to be part of this.

I am particularly grateful to Hannes, Stephan, and Dominik. Hannes, you are the piano man ("Hey Jude") and a true "Daniel Düsentrieb". I would have missed many entertaining moments without you. Stephan and Dominik, I am thankful for many conversations and your advice on things that matter to me. Browno, unsere brüderliche Kameradschaft war und ist ein Garant für unvergessliche Zeiten in Vergangenheit und Gegenwart. Jungs, in Udos Worten waren wir immer unterwegs auf brennend heißer Spur - zwischen Dosenbier und Kaviar. Applaus Applaus, ich bedanke und verneige mich!

Zum Schluss bedanke ich mich bei meinen Eltern Peter und Ruth. Ihr habt mich in meiner persönlichen, sportlichen, und geistigen Entwicklung unterstützt ohne mich unter Druck zu setzen. Danke, dass ihr ein Anker und Rückhalt wart, der es mir erlaubt(e), mit rheinischer Fröhlichkeit durchs Leben zu gehen. Vielen Dank Seb für häufige Praktikerhilfe, denn manchmal ist alle Theorie nur grau. Mein Dank gilt auch Lothar und Ingrid für ihre Großzügigkeit, Hilfsbereitschaft, und die vielen Stunden an ihrem Rückzugsort der Ruhe. Zuletzt sei der größte Dank der Kleinsten. Geraldine, unsere emotionale Verbindung versprüht Glück im Alltag und trumpft in Zeiten der Trauer. Danke für deine Herzlichkeit und Liebe.

Last, I am indebted to Maastricht University for receiving knowledge and education, and for providing an environment that has stimulated my curiosity. Thank you all. 



\section{Table of Contents}

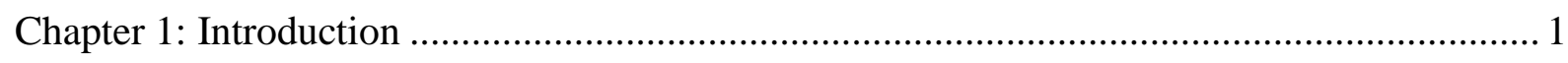

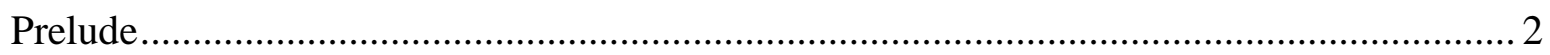

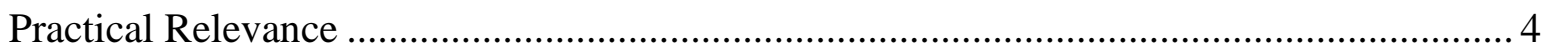

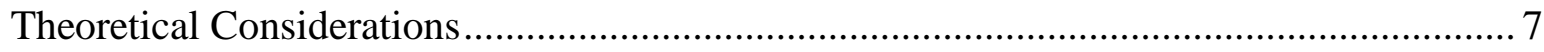

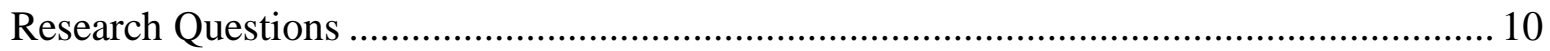

Chapter 2: Moving from the Dark into the Bright Side Again ................................................ 13

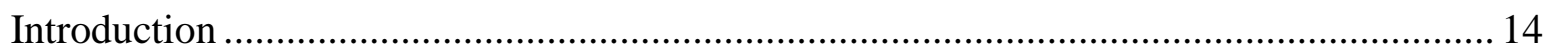

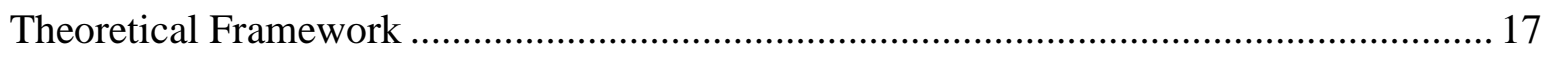

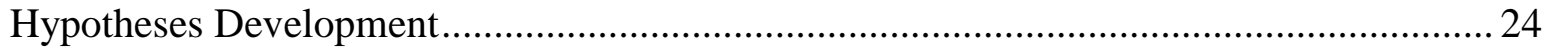

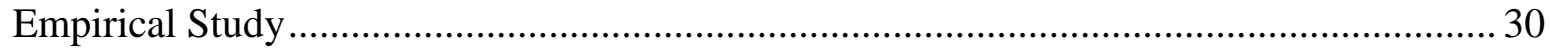

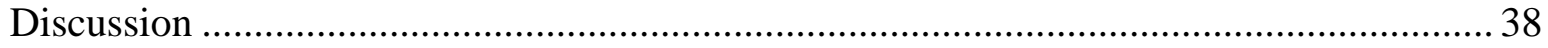

Limitations and Avenues for Further Research............................................................. 43

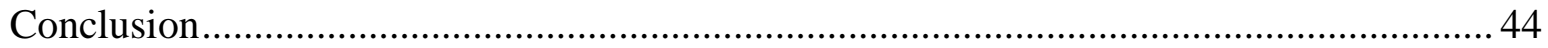

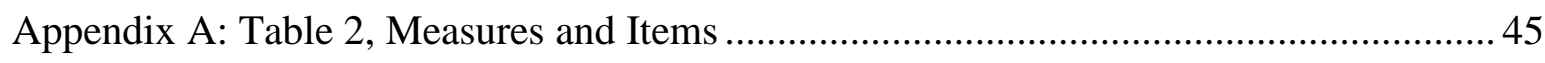

Chapter 3: When Consumers Lose that Lovin' Feeling ......................................................... 47

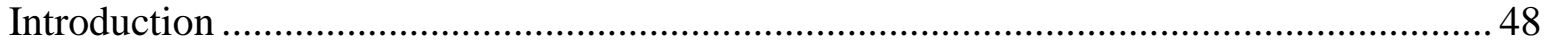

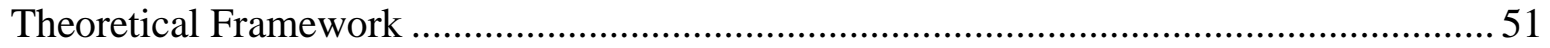

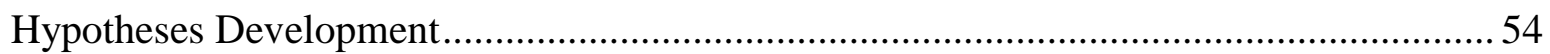

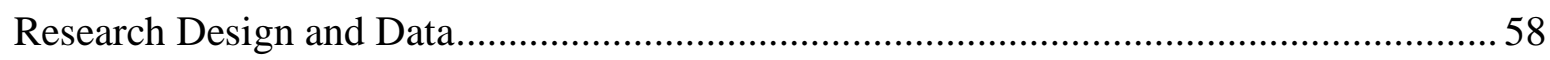

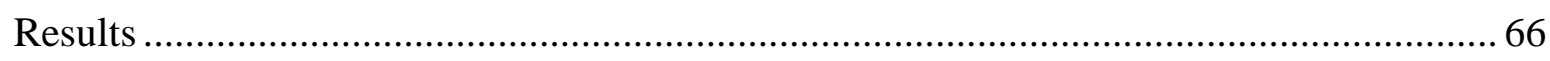

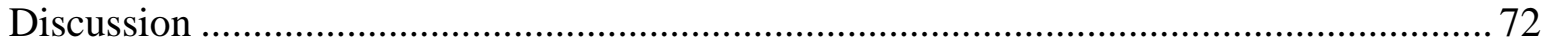

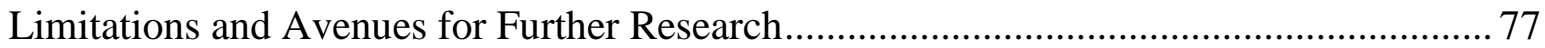

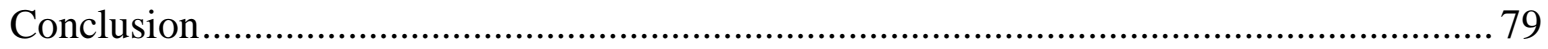

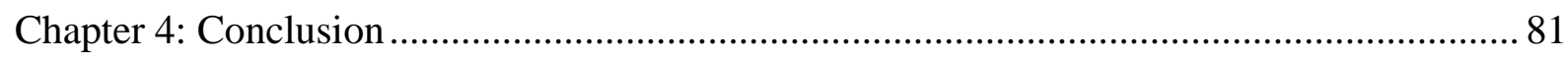

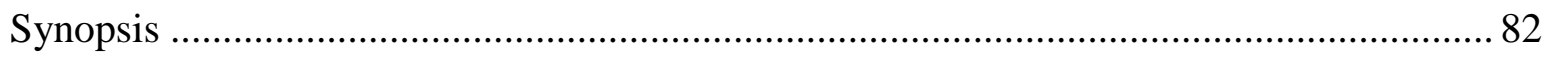

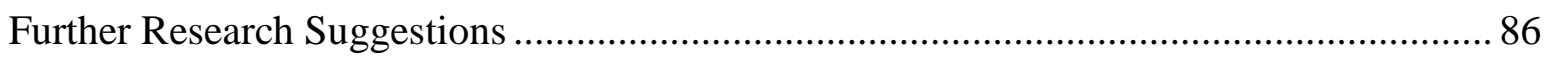

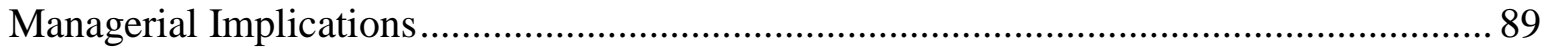

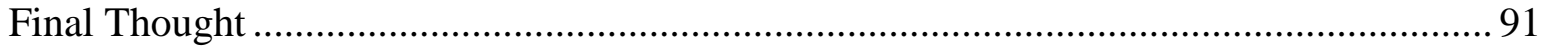

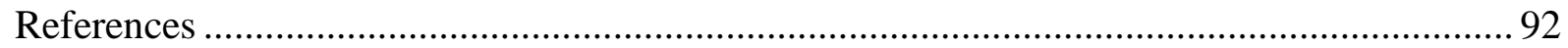

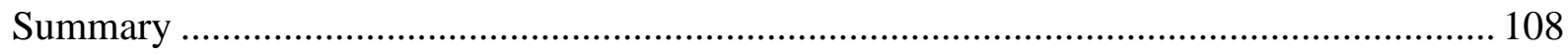

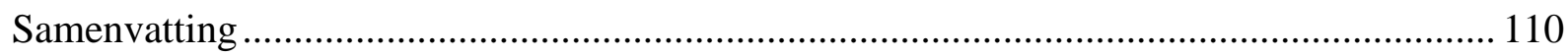


Chapter 1

Introduction 


\section{Prelude}

Tom and Susan have been in a relationship for a long time. After their first date, butterflies whirred around in their stomachs. They spent the first relationship years on cloud nine; everything felt exciting and easy. Both grew closer, adapted and began to feel content over time. In this state of mutual comfort, they developed relationship routines and it seemed as if someone had put the relationship on cruise-control. This relational unawareness lulled them into a passive, almost careless attitude in which they took their relationship for granted. Their relationship subsequently slipped into mediocrity and dark clouds appeared on the horizon. Commenting on the development and status quo of the relationship, Susan says: "Our relational fire is still glowing; it is not out at all. It is still warm enough to cook the food and get us through everyday life. We share a common history, we have been through a lot, but for some reason it seems as if our relationship has become a little stale."

Business relationships can be somewhat similar. Partners meet, familiarize, and if the initiation period is successful, they maintain and deepen the business relationship, expecting benefits for all parties involved. Partners increasingly trust each other, and if both are satisfied with the relationship, they grow the pie and the partnership will go on. However, as the illustration of Tom and Susan shows, even the most successful relationships can change over time and slip into mediocrity. Though both might have been unaware of the behavior which has cemented mediocrity, the consequences are eventually traceable to their behavior (Laughlin 2007).

Paradoxically, the very positive components which build and maintain a successful relationship can supply the breeding ground for relationship decay. For example, common sense tells that the more satisfied partners are with a relationship, the brighter their joint 
future. Yet, relationship satisfaction also produces a feeling of comfort and coziness, which might result in partners' self-satisfaction with the status quo. Either side feels content and does not try as hard to please the partner because the relationship is taken for granted. If partners put the relationship on such "cruise control", they might easily fall asleep at the wheel damaging the relationship. Andrew Grove, former CEO of Intel Corporation, remarks: “Success breeds complacency. Complacency breeds failure. (...).” (Wikipedia 2013).

In fact, a mutual increase in relationship trust - another important factor in building a relationship - may cause negative effects, such as complacency or indifference to emerge. When partners do business for the first time, they put their toe in the water and increasingly build up trust. Exchanges become more efficient as mutual trust grows from low to high levels. Yet, blind trust also loosens control mechanisms. People stop monitoring, which might encourage opportunistic behavior or cheating of either party, so that the relationship eventually deteriorates. The story is not much different for mutual dependence. Many romantic partners raise kids and buy a house together. Business partners share assets, information systems or personnel to denote one's long-term commitment to the relationship. Yet, acts of relationship over-dependence also imply vulnerability; one partner is left powerless and defenseless in the event of negative actions of the other.

These examples point to substantial costs which might arise out of and co-exist with positive relational ingredients, such as satisfaction or trust. Given the central role of long-term relationships in the marketing literature, this thesis suggests new insights on the temporal development of relationships and appropriate measures to keep them vibrant. 


\section{Practical Relevance}

\section{The paradox of long-term relationships}

Be it in a private or professional sense, long-term relationships are fundamental to human cooperation because "man is by nature a social animal" (cf. Aristotle). In the business domain, relationship management has experienced an explosive growth and is nowadays a strategic imperative to gain competitive advantage (Palmatier et al. 2006; Srinivasan and Moorman 2005). Between 1996 and 2001 for example, companies engaged in more than 57,000 alliances (Dyer, Kale, and Singh 2004). Nike, the world's largest shoe producer, does not actually manufacture a single shoe, thanks to established close relationships with suppliers who have taken over the whole manufacturing process (Elmuti and Kathawala 2001). Primarily, firms recognized that developing and deepening key relationships with important stakeholders, be it other firms or customers, leaves all parties "better off" (Hibbard et al. 2001). Overall, there is wide-spread consensus that proficient relationship management drives business performance in both a business-to-business (B2B) and a business-to-consumer (B2C) setting (Hibbard et al. 2001; Ryals 2005).

Yet, building close long-term relationships can also come at a cost. Up to $50 \%$ of joint-ventures fail and typically many relationships sour over time and are hence dissolved (Beamish 1985). Additionally, successful long-term relationships which are well functioning seem to change over time, incurring hidden costs (Scheer 2012). Recently, there has been more evidence for the emergence of negative side effects in the relationship marketing literature, particularly in B2B settings. Anderson and Jap (2005) note that business relationships sour over time, but despite performance problems, partners often shy away from relationship termination. Likewise, relationship length, which should actually signal relationship stability, seems to catalyze the financial decay of relationships (Hibbard et al. 
2001). This phenomenon of diminishing returns ultimately demonstrates a dark side of relationship marketing efforts (Dant and Gleiberman 2011). The central question is: Why do some relationships change over time and what causes relational slack? The reasons for downward trends in relational performances are manifold. Perhaps one central reason is that the more comfortable people feel in a relationship, the more likely they are to broach unpleasant issues yielding potential for conflict (Ephross and Vassil 1993). At the same time, there is no simple "walk-away option" for either partner as both have made substantial investments idiosyncratic to the relationship (Williamson 1985). Given such high relationship exit barriers for each side, it seems a challenging task to keep a constructive esprit de corps to preserve relational productivity. Hence, the first study of this dissertation systematically reviews the reasons for possible profitability corrosion, known as the dark side, in progressed stages of $\mathrm{B} 2 \mathrm{~B}$ relationships (Chapter 2). Based on this review of the state of the art literature, the dark side is conceptualized and suitable suppressor strategies are proposed.

Downwards trends in ongoing long-term relationships have been mainly identified in B2B relationships, perhaps because these relationships mimic "real relationships" more adequately. Compared to many consumer-brand relationships, B2B relationships are more interpersonal and more complex due to higher switching and sunk costs in the case of relationship dissolution. Yet, such negative effects might not be exclusively limited to interpersonal B2B relationships. Consumers also form long-term relationships with brands (Fournier 1998). Some consumers, so called "brand zealots", are so infatuated with particular brands that they form mental relationships to realize emotional benefits beyond basic practical needs (Rozanski, Baum, and Wolfsen 1999). Similar to how they treat human beings, they give names to their VW Beetle and strike it with affection (Aggarwal 2004). Others regard an Apple MacBook as their best friend (Lovemarks 2013). In fact, some brands encourage 
consumers to see them as a humanlike relationship partner. Build-a-Bear for example produces furry bears that the company sells as a kid's first real friend (Clark 2013).

Companies have sound reason to build and sustain relationships with consumers. A recent industry report reveals that investing $\$ 1$ into customer relationships yields an average return of $\$ 5.6$ to the firm (Nucleus Research 2011). On the other hand, some studies point to apposite symptoms of longer customers being not necessarily more profitable (Reinartz and Kumar 2002). Though generally, such outcomes are attributed to poor implementation of a relationship management system (Reinartz, Krafft, and Hoyer 2004). However, similar to the dark side in the B2B literature, these symptoms might be traceable to psychological, intrarelationship developments which inevitably occur as time passes. Looking through this lens, my research attempts to investigate whether customer-brand relationships are prone to a similar downward trend that affects customer loyalty. In this vein, the temporal inspection of customer-brand affections might serve as a new explanatory mechanism in the field of proactive customer retention management (Sun, Li, and Zhou 2006). The temporal examination of customer-brand affections might yield first insights about a potential decline, undermining customer profitability. Thus, we analogously propose a pre-emptive measure to suppress this dark side symptom in a B2C context (Chapter 3). 


\section{Theoretical Considerations}

Several psychological processes affect the course of a relationship. Drawing on central constructs in the marketing literature on building and maintaining relationships, this dissertation examines two major frameworks to understand why positive relationships between business partners, or between consumers and brands, change over time.

First, we consider possible psychological mechanisms that might underlie performance deterioration in B2B relationships. It is commonly known that dark side effects emerge in well-functioning relationships, yet it is unclear as to what specifically constitutes this dark side in exchange relationships. Drawing on the basic principles of social exchange theory, we conceptualize buyer complacency as focal dark side construct, which in turn feeds other negative relational sentiments. As a next logical step, we develop strategies based on previous literature to suppress dark side symptoms in exchange relationships.

Second, we consider possible psychological mechanisms that underlie performance variations in $\mathrm{B} 2 \mathrm{C}$ relationships. While the literature is relatively silent about dark side effects in consumer-brand relationships, some authors identify profitability corrosion of long-term customers in specific settings. The state-of-the-art literature tells that customer brand affections play a central role in the successful maintenance of consumer-brand relationships (Yim, Tse, and Chan 2008). Drawing on hedonic adaptation theory, we explain why the temporal pattern of brand affections might change over time, corroding customer retention (Frederick and Loewenstein 1999). As a next logical step, we conceptualize happiness sustaining interventions as a novel mechanism to forestall hedonic adaptation effects. 


\section{Social Exchange Theory}

For study one, social exchange theory (SET) is the theoretical point of departure to understand why partners maintain or dissolve relationships. In its most basic sense, SET states that the decision to preserve or dissolve a relationship is based on fundamental rules of reciprocity (Thibaut and Kelley 1959). Individuals balance relationship costs versus benefits and this assessment is benchmarked against the attractiveness of alternatives in the market (Anderson and Narus 1984). Grounded in SET, there is a large volume of relationship marketing literature showing, that founded upon trust, partners oblige to rules of exchange over a series of transactions and attain high relationship quality, which promotes relational cooperation, productivity, and efficiency (Morgan and Hunt 1994; Thibaut and Kelley 1959).

Accordingly, this angle is useful for our first study to understand why and how negative symptoms might emerge over time in trustful B2B relationships. In a buyer-supplier context, the emergence of dark side symptoms should, in line with SET, result in an increase of relationship costs, which might possibly cause relationship dissolution. Oddly enough, buyers often remain loyal to a particular supplier, despite a gradual decrease in relationship attractiveness (Hibbard, Kumar, and Stern 2001). Hence, we draw on SET and complement its traditional perspective with psychological explanations to understand why buyers stop monitoring relational exchanges over time and against their own best interest. Specifically, we conceptualize buyer complacency and three other distinct dark side constructs which determine how partners assess exchanges in ongoing relationships and available substitutes.

\section{Hedonic Adaptation Theory}

Hedonic adaptation theory is the central framework for our second study. It posits that people emotionally adapt to positive experiences so that affective reactions abate with time (Frederick and Loewenstein 1999). People adapt surprisingly quickly to trivial consumption 
experiences, such as repeated eating of one's favorite ice-cream (Kahneman and Snell 1990) and impactful life events, such as winning the lottery (Brickman, Coates, and Janoff-Bulman 1978). The underlying mechanisms for adaptation are psychological and physiological processes that foster coping to safeguard peoples' emotional systems. This is desirable because our emotional system cannot function properly in states of constant emotional arousal (Lyubomirsky et al. 2011). What's more, positive experiences change peoples' reference points for successive experiences, so subsequent affective reactions must strongly differ from the established threshold to be noticeable.

Many brands center around building and sustaining emotional ties with customers to differentiate themselves from competition (Berry and Carbone 2007). Since customers emotionally adapt to positive consumption experiences (i.e., services) and products over time, the question arises whether existing customers also adapt to brands over time. As a result, our second study examines how hedonic adaptation affects consumer-brand relationships. Subsequently, we study effective ways to maintain affect-based relationships, and ultimately customer loyalty (Yim, Tse, and Chan 2008). 


\section{Research Questions}

The state-of-the-art literature suggests that in the course of time, even the best B2B relationships yield progressively weaker returns. The fundamental research problem of this dissertation arises from the outlined gaps in the marketing literature on developing viable strategies to manage and sustain profitable long-term relationships. To generate further theoretical and managerial insights on this, two quantitative studies have been conducted in the B2B and the B2C context. The first study focuses on the B2B domain and delves into the underlying constructs which constitute the dark side of relationship marketing to explore their interconnectedness. That way, it opens a veritable Pandora's Box to deepen our understanding about what exactly constitutes the dark side. After the conceptualization of the dark side, it contributes to the limited, yet emerging, body of literature on suitable suppressor strategies to safe-guard buyers from relational over-investments. The second study focuses on the B2C domain and attempts to unveil whether similar relational downward trends occur in long-term consumer-brand relationships. Thus, it contributes to contemporary research by inspecting the emotional trajectories of consumer-brand relationships. In turn, it generates insights about possible levers to influence customer brand affect, and in turn customer loyalty.

\section{Chapter 2: $\quad$ Moving from the Dark into the Bright Side Again: Suppressing Buyer Complacency in Long-Term Business-to-Business Relationships}

While firms continuously seek to grow the pie by forging closer relationships, they struggle to combat the relational decline in the passage of time. To gain a nuanced understanding about the dark side and offer more guidance on how to fight it, this study sampled 75 MBA students in a pre-test, and 136 purchasing professionals in the main study. 
Partial least squares path modeling (PLS PM) is used to answer the following research questions:

$\mathbf{R Q}_{1}$ : Which symptoms constitute the dark side in close relationships?

$\mathbf{R Q}_{2}$ : How do the different dark side symptoms inter-relate and how do they impact the attractiveness of relationship alternatives?

$\mathbf{R Q}_{3}$ : Given the inevitable onset of the dark side, what are viable suppressor strategies to mitigate dark side symptoms in business relationships?

Chapter 3: When Consumers Lose that Lovin' Feeling: Planned Experience Interventions to Emotionally Recharge Consumer-Brand Relationships

Despite the equivocality that customer longevity is positively related to profitability (Reinartz and Kumar 2002), many firms prioritize sustaining emotional relationships with existing customers (Reichheld 1996). For that purpose, the second study suggests examining changes in customer brand affection and tests experience interventions to ward off destabilizing effects on customer retention due to an emotional decline. Panel data from a field experiment with 822 automotive customers are used and selective findings are replicated with a lab study among 289 business students. We conduct repeated measures (RM) ANOVAs and logistic regression models to empirically answer the following research questions:

$\mathbf{R Q}_{1}$ : Do existing consumer-brand relationships follow an emotional decline in the passage of time?

$\mathbf{R Q}_{2}$ : Can planned experience interventions serve as a mechanism to mitigate this potential decline?

$\mathbf{R Q}_{3}$ : How should firms design experience interventions most effectively to mitigate this potential decline? 
After delving into the above outlined six research questions in chapters two and three respectively, Chapter four will finally summarize and integrate the main findings from the previous chapters, i.e., how relational downward trends can be overcome. In the light of these findings, we will discuss theoretical and managerial implications and point to future research opportunities in the field. 
Chapter 2

Moving from the Dark into the Bright Side Again - Suppressing Buyer Complacency in Long-Term Business-to-Business Relationships 


\section{Introduction}

For the few last decades, the general consensus in the business-to-business (B2B) literature suggested that buyers should forge close partnerships with suppliers to achieve competitive advantage (Jap 1999). Many prominent companies are paying heed to this advice. For example, Unilever has installed a preferred supplier program to streamline business processes (Unilever 2012). Others have taken the suggestion further, and now even the closest competitors sometimes collaborate, before and after lawsuits. Apple, for instance, has its major competitor, Samsung, manufacturing $26 \%$ of its iPhone components (Crothers 2011).

Needless to say, that many buyer-supplier relationships (BSRs) turn sour and eventually fail because of persistent disagreements, hostile conflicts, or structural problems (Elmuti and Kathawala 2001). However, beyond such visible incidents, hidden costs affect long-term relationships which otherwise appear to function smoothly (Scheer 2012). A recent study among industrial buyers revealed that relationship closeness is actually detrimental to their performance in turbulent technologically markets, most likely due to relational complacency (Terawatanavong et al. 2011). Examining BSRs in the telecommunication industry, Brennan (1997) finds that buyers often renew contracts almost automatically, making potential competitors stop bidding against the entrenched supplier because of the perceived futility of the action. Similarly, companies like Dell experience complacency among the company's buyers as these employees neglect treating long-term suppliers as "tough customers", thus losing out on potential cost savings or innovations (Schmid and Vogl 2003). In an effort to understand this quietly detrimental phenomenon, Anderson and Jap (2005) sampled 1,500 business relationships and conclude that good relationships drift into a state of deteriorating performance as partners become increasingly passive. Yet, there is little understanding about what constitutes this so-called "dark side" of close relationships and 
what creates "forces of destruction that are quietly building beneath the surface of the relationship" (Anderson and Jap 2005, p. 75). Buyers, who should actually drive B2B relationships, apparently are prone to fall asleep at the proverbial wheel, causing relationship slack and possibly relationship termination.

The extant literature on business relationships, unfortunately, offers little guidance as to the underlying mechanisms which cause the emergence of relational slack (cf. Hibbard et al. 2001; Pressey and Tzokas 2004). This phenomenon emerges because traditional exchange theories assume that buyers continue and maintain relationships as long as the benefits outweigh the costs. Dark side effects, however, are nested exclusively in healthy relationships, and manifest despite high levels of relationship quality. The manifestation of such symptoms becomes observable when high levels of relational trust or commitment decline in their ability to steer performance (Hibbard et al. 2001). While switching or termination costs might be one rational reason to tolerate relationship deterioration (Williamson 1985), there is a relative paucity of knowledge regarding why positive relationships become stale over time. In turn, this gap logically implies that there is even less understanding about preventive strategies to combat the deterioration of relationships. Anderson and Jap (2005) make a first attempt by deriving managerial suggestions to fight the dark side, but their seminal work has not been subjected to empirical corroboration.

To address these gaps, we complement the relationship marketing literature with insights from the ergonomics literature to understand the psychological and economic factors that cause positive relationships to deliver progressively weaker returns. In this literature, the central focus is to define optimal monitoring behavior when operators work with highly reliable systems. Similar to pilots that monitor their well-functioning flight system less than optimally (Moray and Inagaki 2000), buyers' economic motivation to monitor a relationship might paradoxically go down over time, producing other negative relational effects against 
their own best interest. Attention management strategies from ergonomics can guide managers in the timely detection of problems, as inattention may cause buyers to lose the ability to objectively evaluate the relationship partner (Moorman, Zaltman, and Deshpande 1992) or take a healthy relationship for granted, in effect, putting it on cruise-control (Dant and Gleiberman 2011). While deriving strategies to overcome problems of suboptimal relationship monitoring, we make the following contributions to the literature.

First, we offer a fresh perspective for understanding the causes of the emergence of negative effects in well-functioning $\mathrm{B} 2 \mathrm{~B}$ relationships. Complementing a perspective in line with social exchange theory (SET), we introduce and operationalize buyer complacency as a focal construct to help realize why buyers stay surprisingly loyal despite diminishing returns. Secondly, we explore the interrelationships between complacency and other negative sentiments, which might weaken the attractiveness of the relationship partner. Thirdly, we draw on what Moray and Inagaki (2000, p. 356) call "a keen situation awareness" to derive a set of viable suppressor strategies. We subsequently test the appropriateness of these strategies empirically to conclude how to arrest buyer complacency and any associated negative sentiments. Given the inevitable onset of the dark side, managerial insights are relevant because close partners need strategies to be ever vigilant (Terawatanavong et al. 2011).

In the next section, we review the literature on the emergence of the dark side and elucidate potential conceptual underpinnings. We then suggest a number of suppressor strategies to avoid the onset of the dark side in long-term relationships. Based on an empirical study among purchasing professionals, we test our conjectures and derive theoretical and managerial implications. 


\section{Theoretical Framework}

Social exchange theory is possibly the most prevalent conceptual paradigm that has been used to further an understanding of how and why buyer-supplier dyads realize synergistic benefits (Thibaut and Kelley 1959). It states that social exchange is dependent on a series of interactions which generate norms and obligations (Emerson 1976). Such norms and obligations contribute to the evolution of the relationship from a simple transaction, to a longterm commitment founded upon trust. Trust and commitment in turn promote favorable outcomes such as relational efficiency, productivity, and effectiveness (Morgan and Hunt 1994). This is because parties are normally "interdependent and contingent on the actions of another" (Cropanzano and Mitchell 2005, p. 875) and hence, they look beyond short-term inequities and risks to preserve good relationships and resist attractive short-term alternatives (Luo 2002). Ultimately, this makes both buyer and supplier better off as they take from a larger "pie" than they would if both parties had worked on a transactional basis (Jap 1999). In the long-term, parties maintain healthy relationships as long as exchanges are reciprocal, fair, and in balance (Anderson and Narus 1984).

Despite the positive performance effects associated with strengthening trust and forging commitment, many partnerships turn sour as a result of conscious and destructive acts, captured by constructs of conflict (Hibbard, Kumar, and Stern 2001; Skinner, Gassenheimer, and Kelley 1992) or perceived unfairness (Samaha, Palmatier, and Dant 2011). Note however, that such negative effects are not associated with the dark side, but rather with clearly identifiable, structural relationship problems. Anderson and Jap (2005) contend specifically that dark side effects are conceptually distinct from relationships which have deteriorated due to poor management or conflict. In contrast to overt conflicts, dark side 
effects are not apparent because they are subtle and take root in positive relationship ingredients, such as high trust or dependence.

Reviewing the literature for dark side symptoms, Moorman et al. (1992) were the first to discover that long-term relationships make partners become stale and myopic in their thinking, thus losing the ability for objective performance evaluations. Brennan (1997) discusses examples of "muted market incentives" when buyers sometimes erroneously renew contracts without even consulting alternative offers and correspondingly, competitors of preferred suppliers resign from even making counter offers (Brennan 1997). In the same vein, Selnes and Sallis (2003) warn that high levels of trust between a buyer and supplier impede the effect of relational learning on performance. Partners seem to cement the status quo and become unaware of learning activities. Thus, buyer-supplier closeness may breed complacency and resistance to innovation in conditions of technological turbulence (Terawatanavong et al. 2011). Scheer (2012, p. 334) sees complacency as "a natural byproduct" of a reciprocal increase in trust leading to blindness, and an underestimation of relational costs. Finally, there is conclusive empirical evidence for profitability corrosion in close B2B relationships (Anderson and Jap 2005; Hibbard et al. 2001), as too much social capital hurts buyer performance (Villena, Revilla, and Choi 2011). In line with SET, relationship maintenance is logical as long as the relationships yield a positive net effect. Unfortunately, profitability corrosion suggests that buyers may increasingly over-invest in the relationship. SET would predict action to resolve this imbalance, but buyers often remain passive and continue the relationship. Additionally, emerging literature on customer entitlement contends that customers stay demanding in making exchanges, which includes monitoring alternative offers or exploiting joint learning activities (Butori 2010). Thus, while the literature contains many instances of predominantly implicit manifestations of 
complacency as a mechanism that corrodes relationships, the construct has never been properly conceptualized in the dark side relational context.

Therefore, an important objective of this paper is to introduce buyer complacency as an underlying mechanism to explain why relationships become stale and deliver progressively weaker returns, consequently offering a theoretically-grounded conceptualization. In its most general sense, complacency is defined as "self-satisfaction especially when accompanied by unawareness of actual dangers or deficiencies" (Merriam-Webster Dictionary 2013). This definition has several implications when applied to the behavior of buyers and therefore, may only serve as a point of departure for further, context-specific conceptual delineation. Selfsatisfaction might naturally arise since the dark side occurs in positive relationships only (Anderson and Jap 2005). Good past performance can lead to false feelings of confidence, coziness or even arrogance (Reece 1994). Hence, we theorize that buyers fall prey to a status quo bias which makes it easier for them to rationalize relationship continuity despite the onset of the dark side. In fact, good past performance causes a decline in the motivation to respond to actions of rivals (Jayachandran and Varadarajan 2006).

Such positive-to-almost narcissistic feelings associated with complacency fit with recent research on customer entitlement literature grounded in the narcissism construct (Boyd and Helms 2005). Automatic compliance due to a customer-is-king mentality can even amplify buyer complacency. Receiving the service of "servants" contributes to situation unawareness so that buyers ignore potential dangers and see no need to explore other market opportunities. At the same time, high levels of relational trust encourage buyers to relax control mechanisms and consequently, they spend less attention on preferred or alternative suppliers, and reduce cognitive effort in managerial decision making (Selnes and Sallis 2003). Previous work confirms this by showing that good past performance causes lower awareness about competitors' actions (Deshpande and Gatingon 1994). Repeated transactions might also 
cause a process of adaptation or boredom (Helson 1964), so that high relationship productivity is taken for granted and barely noticeable for the buyer. To further delineate a conceptualization, Merriam-Webster's general definition is helpful because buyer complacency is indeed a state of self-satisfaction and unawareness. Yet, in a relationship management context, the process of building up high-to-excessive levels of trust seems to be the underlying mechanism that breeds complacency in the first place. Hence, buyer complacency is a state of self-satisfaction and unawareness due to blind trust that has emerged over a series of relational transactions.

Moray and Inagaki (2000) analyze the existence of complacency in ergonomics sciences, offering further definitional insights. Human operators who monitor a fairly reliable aircraft system might miss important signals because they trust the system too much after prolonged exposure. Hence, the state of operator complacency is characterized by "a lack of vigilance" which causes sub-optimal monitoring of a putatively reliable system (Parasuraman, Molloy, and Singh 1993). Linking these insights to SET, excessive trust exacerbates costs of which buyers are not aware. The phenomenon of complacency seems to challenge the traditional assumptions of SET that partners realize benefits based on trustful relationships and that partners are vigilant in assessing exchanges.

While sub-optimal monitoring is undesirable as discussed previously, monitoring a system more often than required is similarly unappealing as operator workload increases by taking redundant samples (Moray and Inagaki 2000). These benefits conform to SET because building up trust makes exchanges more efficient (Morgan and Hunt 1994). Also, a buyer's “skeptical" over-monitoring might cause supplier suspicion. To reduce complacency, Moray and Inagaki coin the word "eutactic" (Greek: suitably trained) to specify monitoring behavior which is optimally required given a particular source. Applying this to a relationship context, it might be that a buyer appropriately monitors "key variables" of the relationship, but the 
information system or a lack of training leads him/her to make uninformed decisions. Likewise, s/he might monitor variables which are unimportant to the relationship. Hence, the conclusion is that complacency implies defective monitoring only, not necessarily missed signals or faults. Previously, we incorporated the term "unawareness" in our attempt to conceptualize relational buyer complacency. Yet, the term situation unawareness is poorly specified because it implies that a buyer is aware of all important variables and reacts appropriately in case of abnormal events (Endsley and Garland 2000). Given the number of infinite events which can change, Moray and Inagaki (2000) contend that it is difficult to execute a eutactic monitoring strategy for an endless set of dynamic variables.

To conclude, we advance the context-specific delineation of buyer complacency as follows. Complacency emerges as a result of too much trust and represents a state of selfsatisfaction accompanied by a sub-optimal monitoring of relational key parameters. The latter part of the definition adds that complacency is explicitly about monitoring, not necessarily about fault detection. The term "unawareness" is more general and points to the failure to recognize the need for change, yet it might be somewhat imprecise. Should buyers be expected to be aware of all potentially dangerous parameters to be complacent? Clearly, an elaboration of what constitutes relational key parameters enhances "a keen situation awareness" to prevent negative effects of complacency. The adjective "keen" might imply that major abnormal events are registered which also takes costs and pay-offs of monitoring behavior into consideration. A manager's keen situation awareness ("What have I done lately for the relationship?") hence contributes to the prevention or realization of the actual state of complacency. Complacency can also become a person's character trait over time (Moray and Inagaki 2000) and be indicative of non-thoroughly monitoring current and future implications of important relationship actions. Since complacency is theoretically traceable to paying little 
attention to important relational parameters, we view it as a central construct to capture the early onset of corrosive forces in long-term relationships.

While the onset of the dark side is subtle, the realization of a buyer's own complacency ("I have been careless about the future implications of my actions") might induce more overt negative feelings (Pearlin et al. 1981). Feelings of vulnerability might arise because blindness has led to overinvestments in a supplier who is incapable of staying at the forefront (Brennan 1997; Scheer 2012). The realization of having over-trusted a business partner could also trigger myopic feelings of being overly attached to relational routines, short-sightedness, and narrow in defining the business perspective (Levitt 1960). Anderson and Jap (2005) observed a spiral of suspicion for 220 business partnerships; parties begin to modify their behavior if they think they have trusted too much. All such negative sentiments can impede relational continuity while increasing the attractiveness of substitutes in the market.

Several studies offer a discussion about the next logical question: How to best mitigate or prevent the emergence of dark-side symptoms? Anderson and Jap (2005) are one of the firsts in this respect. They develop an inventory of preventive strategies which center around three remedies to keep the dark side at bay: (1) making relational decay functional (e.g., by reevaluating older relationships), (2) capitalizing on personnel, (e.g., by relying on a group instead of an individual relationship manager), and (3) suppressing conflicts to linger (e.g., by specifying common goals and assets). Dant and Gleiberman (2011) build on these suggestions using marriage counseling and marriage and relationship education literature. Some of their preventive strategies, such as specifying common assets, overlap category three, "suppressing of conflicts," of Anderson and Jap. They also develop combative strategies, for example the re-evaluation of relationship needs and common goals, which partly overlap Anderson and Jap's category one and three of preventive strategies. Finally, Villena, Revilla, and Choi 
(2011) make some suggestions which again refer to making relational decay functional and capitalizing on personnel.

In sum, there is still little coherence regarding the theoretical development of viable suppressor strategies. Perhaps this is because the dark side has not been clearly conceptualized, and was broadly understood as a phenomenon of "diminishing returns" (Baker 2009). There is also confusion about the efficacy of the proposed strategies because all papers lack empirical verification to build up systematic knowledge. Nevertheless, some strategies crop up repeatedly, if we ignore the disagreement in labels and classifications of being preventive or combative. To group them and complement the original classification by Anderson and Jap, there is a common denominator to prevent relational slack by the reevaluation of older relationships, and the fostering of discussions about potential alternatives to safeguard relational profitability. We note that these strategies are somewhat unidirectional because buyers could employ them rather independently. With respect to capitalizing on personnel, there is consensus about involving a relationship team instead of a single manager to make decisions. Ideally, this is a dyadic strategy to avoid relationship complacency, yet buyers could also install it as an organizational control mechanism to prevent buyer complacency only. Thirdly, to avoid the appearance of latent conflicts, the specification of common goals seems productive. In this vein, the specification of dedicated assets might also help to increase exit barriers and put the relationship "back on track". Specifying common goals and assets are more dyadic suppressor strategies, because these require joint collaboration efforts of buyers and suppliers. We build on these qualitative thoughts and integrate them with our conceptualization of the dark side to derive hypotheses. Logically, we adhere to the basic notion that strategies ought to promote relationship continuity because switching costs can be substantial due to high investments or legal proceedings, even in the case of a pragmatic relationship dissolution (Tähtinen and Vaaland 2006). 


\section{Hypotheses Development}

As complacency and the associated costs unfold over time in BSRs, buyers shall periodically re-evaluate older relationships to avoid a take-it-for-granted mentality (Anderson and Jap 2005). Re-evaluation represents a thoughtful assessment of the status quo of the relationship and acts as an overall relationship barometer of progress (Dant and Gleiberman 2011). Regular meetings and dialogues can help buyers to assess the relationship status and review latest developments. This creates a keen situation awareness which is necessary to internalize that value dimensions are dynamic (Beverland, Farrelly, and Woodhatch 2004; Flint, Woodruff, and Gardial 1997) and business success is not continuous (Bergquist 2006). Thus, meetings to re-evaluate older relationships might help buyers, who are in the driver's seat of the relationship, to stay away from "putting a healthy relationship on cruise-control" (Dant and Gleiberman 2011). Likewise, research on romantic relationships signals that couples who engage in planned re-evaluations renew relationships more successfully (Nelson et al. 2008). Thus, we hypothesize:

$\mathrm{H}_{1}$ : Re-evaluation will have a negative effect on buyer complacency.

Demand-side complacency arises because buyers trust too much, act carelessly, and see no need for change of the cozy present. Hence, there is good reason to believe that buyers lose connection to and information about potential substitutes in the market, which undermines the role of an active customer. Yet, it might be important to play the field from time to time to discover whether other suppliers have better offerings (Dant and Gleiberman 2011). Screening alternative suppliers manifests the examination of the status quo, which defies self-satisfaction. Besides, informing a supplier about the screening of potential substitutes should motivate the supplier to maintain competitiveness (Burt, Dobler, and 
Starling 2003; Hanvanich, Sivakumar, and Hult 2006). Hence, constantly updating market knowledge is another control mechanism to prevent sub-optimal monitoring. Thus:

$\mathrm{H}_{2}$ : Screening exit-options will have a negative effect on the emergence of buyer complacency.

Often, an individual buyer manages several key suppliers. While this may be efficient and profitable, individual buyers can lose objectivity and become blind over time. For this reason, it might be helpful to have multiple buyers as opposed to one individual managing key suppliers (Hult and Nichols 1999; Kale and Singh 2009). Despite the additional costs and potential inefficiencies of this measure, rotating buyers in and out might preserve a solid composition of people, who are without "relational scars" and hence more objective negotiators (Swaminathan 2006). The composition of a team of buyers with different relational tenure equals the installation of a collective monitoring system, as team members monitor each other. This practice automatically prevents a state of self-satisfaction because new team members are less attached to and familiar with relational routines. Hence, they tend to question existing knowledge, the adequacy of relational routines, and their success (Jordan, Messner, and Becker 2009). Thus, we hypothesize:

$\mathrm{H}_{3}$ : The implantation of collective structures will have a negative effect on buyer complacency.

Lund (1985) finds that relationship investments, be it monetary or emotional, positively affect relationship longevity of romantic relationships. In a business context, transaction cost theory tells that dedicated assets or human processes, which are relationship specific, increase exit barriers and thus reduce the likelihood of opportunistic behavior 
(Ghoshal and Moran 1996; Nielson 1996). If dedications are joint and equal, high interdependence fosters reciprocity and forms a mechanism for joint profit optimization (Hibbard, Kumar, and Stern 2001). These financial gains might be used to fund innovative exploration again (March 1991), so that buyers improve the satisfying status quo of a mature relationship. At a minimum, buyers who communicate investments and share reports in how far they have dedicated themselves to the relationship signal the psychological motivation to improve the status quo. Hence, the malaise of buyer complacency should alleviate, if buyers regularly monitor and communicate relationship investments. Hence,

$\mathrm{H}_{4}$ : Communicating dedicated assets will have a negative effect on the emergence of buyer complacency.

At the beginning of a relationship, partners define important relationship goals but these might fade if they become self-satisfied and trust too much. To review and adjust these goals, buyers must draw constant attention on what is at stake and what was at stake (Jap and Anderson 2003), so that there is no positivity bias about the relational status quo. Creating a document that clearly specifies each parties' obligations and responsibilities might especially motivate the supplier to stay market-oriented, which can prevent relationship complacency, and buyer complacency (Hanvanich, Sivakumar, and Hult 2006). Other than that, social loafing theory posits that loafing occurs once individuals perceive a lack of concrete and specific goals (Harkins and Jackson 1985). Hence, specific goals help buyers to exert more effort and monitor their own performance more adequately (Carver and Scheier 1982; Fang, Palmatier, and Evans 2004). Even though very detailed contracts can harm trust in close relationships (Wuyts and Geyskens 2005), we posit that goal specificity helps buyers to prevent complacent behavior. Thus, 
$\mathrm{H}_{5}$ : Goal specificity will have a negative effect on the emergence of buyer complacency.

As argued above, other dark side constructs might follow after the emergence of complacency. Complacency is rooted in excessive trust and careless monitoring behavior which make a buyer narrow-minded in defining the business perspective, including the ignorance of better alternative offers (Levitt 1960). Putting a relationship on cruise-control nurtures a subsequent state which is opposite to producing new and innovative ideas for the relationship (Johannessen, Olsen, and Lumpkin 2001). Over time, buyers tend to use rigid mental models which hamper changes in thinking (Gronhaug, Henjesand, and Koveland 1999) so that they get over-attached to relational routines, and adopt a myopic perspective as they dedicate little time to innovate the relationship sustainably. The impact of the status quo makes them exploit, but not explore, opportunities so that they are short-sighted in their ability to recognize new benefits from exploratory activities (Holmqvist 2004). Adopting a myopic perspective through mental models might become problematic when environmental and competitive changes require buyers to update relational solutions (Slater and Narver 1994). Thus, complacency feeds feelings of short-sightedness, or relational myopia:

$\mathrm{H}_{6}$ : Complacency has a positive effect on feelings of relational myopia.

From a purely conceptual point, complacency might also foster vulnerability. It is a by-product of high trust (Scheer 2012), and trust is defined as actions that increase one's vulnerability to each another, or as the confidence in each party not to exploit vulnerabilities of the other one (Barney and Hansen 1994). Hence, there might be, per definition, a positive relationship between complacency and vulnerability. Moreover, blindness and outdated 
market knowledge emerge from complacency and can lead to over-investments in a supplier who has lost competitive edge (Brennan 1997). The realization of such costs can trigger feelings of vulnerability because buyers have increased exit barriers, and are left defenseless in case of harmful actions of the supplier. Thus:

$\mathrm{H}_{7}$ : Complacency has a positive effect on feelings of vulnerability.

Next to vulnerability, complacency could also breed feelings of suspicion. A buyer's realization of sub-optimal monitoring might support the belief that the supplier has taken advantage of his/her complacency. To compensate, such a potential disconfirmation of expectations might lead to skeptical over-monitoring and modifications of future behavior (Moray and Inagaki 2000). The buyer might subsequently follow a more individualistic than a cooperative orientation and scrutinize supplier actions more closely (Deutsch 1958; Kee and Knox 1970). The supplier in turn, might respond with hostility or withdrawal when confronted with such feelings of suspicion. Even if the partnership continues both partners might remain perceptually disgruntled for no good reason. In fact, seemingly minor issues can cause a dysfunctional spiral of suspicion as Anderson and Jap (2005) conclude from confidential interviews of 220 partnerships. Feelings of suspicion then overshadow surfaced feelings of complacency, thus:

$\mathrm{H}_{8}$ : Complacency has a positive effect on feelings of suspicion.

These more overt negative dark side symptoms provide a breeding ground for relationship deterioration, which leads to a decrease in attractiveness of the current supplier. Myopia can produce symptoms of competitive regression in the long-run because buyers are unable to innovate their existing relationship in tune with market dynamics. Buyers then 
question the performance potential of the relationship and explore other partnering options. Likewise, feelings of vulnerability should induce buyers to reduce relational dependence (Heide and John 1988). In fact, previous literature shows that firms offset investments to restore imbalances of dependence, so that relationship substitutes become automatically more attractive (Ganesan 1994; Inkpen and Beamish 1997). Suspicion can nurture dangerous feelings of distrust in BSRs so that parties become untruthful, souring the relationship climate. Overall, a buyer might perceive a loss in attractiveness and performance potential of the current supplier in the light of the emerged negativity, and substitute firms might become more attractive. Hence:

$\mathrm{H}_{9}$ : Feelings of a) myopia, b) vulnerability, and c) suspicion increase the attractiveness of alternative suppliers.

Despite the emerged negativity, high sunk costs might attenuate the positive relationships stated in $\mathrm{H}_{9}$. Investments of time and money are essentially idiosyncratic and can discourage relationship termination (Williamson 1985). A rational assessment would indicate high switching costs, and motivate buyers to get the relationship "back on track" instead of favoring alternative suppliers. Next to the enormous psychological and economic switching costs, good alternatives can be scarce and exiting a current relationship is sometimes more complex than expected (Ping 1994). Jackson (1985) sees that in the light of high sunk costs, buyers and suppliers often remain in less than ideal relationships. Thus:

$\mathrm{H}_{10}$ : High sunk costs attenuate the positive effect between a) myopia and attractiveness of alternatives, b) vulnerability and attractiveness of alternatives, and c) suspicion and attractiveness of alternatives. 


\section{Empirical Study}

Prior to the main study, we recruited a sample of 75 MBA students from a large US university for a pre-test. Based on previous academic research, we derived and adapted measures to operationalize the dark side constructs and the suppressor strategies (see Appendix Table 2). Afterwards, we conducted in-depth interviews with three marketing executives at different organizations to make minor textual adjustments (Jayachandran and Varadarajan 2006).

The results of the measurement validation using PLS path modeling (Chin 1998) revealed favorable psychometric properties. Each construct was operationalized with five indicators, and after dropping some insignificant ones, each construct comprised of at least three reflective indicators. With .84 as the lowest value, all composite scale reliabilities (CRs) compellingly exceeded the cut-off value of .70 and all AVE's were above the .50 threshold proposed by Fornell and Larcker (1981). In support of discriminant validity, the square root of the average variance extracted (AVE) of a particular construct exceeded the inter-correlation with any other construct (Fornell and Larcker 1981). Furthermore, none of the indicators substantially cross-loaded on any other than its associated construct. Finally, we inspected the standardized loadings for each respective construct. All loadings exceeded .65 and all AVE's per construct were higher than the cut-off value of .50 , supporting satisfactorily convergent validity (Hulland 1999).

After the pre-test, we looked for opportunities to collect data in a relevant business-tobusiness context where dark side effects might arise as a phenomenon of partners' engagement in long-term relationships. Previous literature points to buyer-supplier relationships in this regard (Anderson and Jap 2005; Hibbard, Kumar, and Stern 2001). 


\section{Sampling Procedures}

In collaboration with a large purchasing association, we distributed an online survey link among its members. To incentivize participation, respondents were informed in the appeal e-mail that they would be entered into a random lottery draw for a tablet PC and five bottles of champagne.

Respondents were asked to complete the survey keeping a key supplier in mind. They could either choose a key supplier based on the length they have been dealing with that supplier, or on the amount of purchases they have made. In this way, we made sure to capture the essence of an important relationship despite the possible differences in interpretation of a "key" supplier. The first part of the survey set out to capture the status quo of the relationship. Respondents completed general questions about the relationship, including the dark side symptoms and potential supplier alternatives. In the second part, purchasers indicated to what extent the relationship had been subject to contextual, structural problems in the past (e.g., quality deterioration of the product/service, major price increases, production delays etc.). The third part covered the suppressor strategies. Here, respondents indicated to what extent they practice certain strategies to sustain healthy relationships and to overcome relationship deterioration. Finally, the survey concluded with control and classification questions (e.g., demographics).

136 purchasing professionals completed the survey. Participants' average age was 39 years with an average work experience of 15 years. Many of them worked for large, multinational corporations. $79 \%$ were males and the average relationship length of a buyersupplier relationship was approximately seven and a half years. These sample characteristics further support the confidence in the suitability and reliability of the obtained sample. 


\section{Measures}

We used the items from the pre-test for the suppressor strategies and the dark side constructs and slightly adapted the framing to be contextually appropriate. All constructs were measured on a seven point Likert scale, where seven indicates a high level and one indicates a low level of a dark side symptom. For the suppressor strategies, a score of seven indicates employment and one indicates the unemployment of a strategy to suppress the dark side symptoms. Table 2 presents an overview of all multi-item constructs used in this study. Next to these constructs, we measured "Sunk costs" ("I have invested a lot of time and money in this relationship").

Prior to validation, some measures were recoded or reversed to conform directionally to the causal relationships in the model. "Attractiveness of Alternatives" was recoded so that high values (e.g., seven) indicate the attractiveness of a potential alternative firm. Additionally, we created two important control variables. First, we counted the number of structural relationship problems that buyers reported and combined them into a composite index measure, "Relational Problems", ranging between 0 and 5. This is essential since the negative effects we hypothesize are subtle and not traceable to structural relationship problems. Second, we created a measure of total interdependence based on the buyer's dependence on the supplier, and the supplier's dependence on the buyer as perceived by the buyer. Total interdependence is essentially a summation of the two variables (Kumar, Scheer, and Steenkamp 1995).

\section{Measurement Validation}

We used partial least squares path modeling (PLS PM) to validate our measures (Chin 1998). PLS PM places little requirements on the data with regard to multivariate normality (Hair, Ringle, and Sarstedt 2011; Tenenhaus et al. 2005). Hence, PLS PM (e.g., Smart PLS) is 
more suitable to accommodate small samples as opposed to the traditional covariance-based approach (e.g., LISREL) (Hulland 1999; Reinartz, Haenlein, and Henseler 2009). Additionally, PLS PM is more appropriate for models with a large number of manifest variables (i.e., > 25) (Chin 1998; Wetzels, Odekerken-Schröder, and Van Oppen 2009). For the study at hand, these properties are beneficial given the relatively small sample $(n=136)$ and the large (i.e., 35) number of manifest variables in the model.

All CRs exceeded .87, demonstrating a high level of composite scale reliability. No indicators substantially cross-loaded on any other than the associated construct and we could establish discriminant validity applying the Fornell and Larcker (1981) criterion (see AVE's in Table 1 and 2). The standardized loadings for each respective construct exceeded .69, so we can also confirm convergent validity of the measures (Hulland 1999).

Common method variance might be a concern because we only sampled one side of the buyer-supplier dyad. We conducted an exploratory factor analysis with all manifest variables and Harman's single-factor test indicted that the first factor accounted for only $10.0 \%$ of the variance. Hence, common method bias was not of a significant influence (Podsakoff et al. 2003). Additionally, we applied the Schmid-Leiman approach and used principal axis factoring to include one common method factor (Yung, Thissen, and McLeod 1999). The common method factor captured $18.4 \%$ of the variance. Thus, our conclusion is that common method bias is of negligible concern. 


\section{TABLE 1}

\section{Descriptive Statistics and Discriminant Validity}

\begin{tabular}{|c|c|c|c|c|c|c|c|c|c|c|c|c|c|c|c|}
\hline & Mean & S.D. & 1 & 2 & 3 & 4 & 5 & 6 & 1 & 8 & 9 & 10 & 11 & 12 & 15 \\
\hline Re-Evaluation & 5.26 & 1.23 & .72 & .10 & .21 & .06 & .27 & .02 & .01 & .03 & .04 & .04 & .01 & .00 & .00 \\
\hline Exit $\mathrm{Op}$ & 88 & .25 & .31 & .73 & .06 & .00 & .14 & .02 & .01 & .00 & .08 & .01 & .01 & .00 & .00 \\
\hline ve Structures & 4.78 & .23 & .46 & .24 & .72 & .09 & .11 & .01 & .00 & .02 & .01 & .00 & .00 & .03 & .01 \\
\hline tted Assets & .07 & .27 & .25 & .01 & .30 & .80 & .02 & .03 & .04 & .01 & .01 & .00 & .00 & .01 & .01 \\
\hline Goa & .12 & .13 & .52 & .37 & .33 & .15 & .63 & .01 & .01 & .01 & .11 & .01 & .00 & .01 & .00 \\
\hline M & .07 & 1.16 & -.13 & -.13 & -.09 & .16 & -.11 & .68 & .02 & .01 & .24 & .01 & .02 & .02 & .00 \\
\hline $\mathrm{Vu}$ & .48 & .13 & -.07 & -.04 & .03 & .20 & .10 & .15 & .79 & .12 & .14 & .04 & .03 & .00 & .04 \\
\hline 3. Sus & 3.33 & 1.22 & -.17 & -.02 & -.13 & .07 & -.11 & .11 & .34 & .66 & .12 & .01 & .01 & .08 & .02 \\
\hline Con & 3.06 & 1.25 & -.20 & -.28 & -.08 & .10 & -.33 & .49 & .37 & .34 & .69 & .00 & .03 & .00 & .06 \\
\hline 10. Sunk Costs & 5.24 & 1.28 & .20 & .11 & .06 & -.04 & .10 & -.09 & .19 & .11 & .01 & $\underline{\mathrm{NA}}$ & .00 & .01 & .06 \\
\hline onship Length & 7.63 & 6.63 & -.07 & .07 & .00 & .04 & .06 & .15 & .18 & .10 & .16 & -.06 & $\underline{\mathrm{NA}}$ & .03 & .02 \\
\hline 2. Relational Problems & 1.51 & 1.31 & -.03 & .02 & -.17 & -.11 & .09 & -.13 & .03 & .28 & .05 & .09 & .17 & $\underline{\mathrm{NA}}$ & .10 \\
\hline 3. Interdependence & 8.13 & 2.59 & -.03 & .01 & -.09 & -.07 & -.03 & .03 & .21 & .14 & .24 & .24 & .15 & .32 & $\underline{\mathrm{NA}}$ \\
\hline 4. Attractiveness of & 2.85 & 1.21 & -.11 & -.16 & -.22 & -.13 & -.21 & -.12 & .35 & .42 & .10 & -.05 & -.04 & .15 & .23 \\
\hline
\end{tabular}

Alternatives

Note: Average variance extracted (AVE) on the diagonal and correlations among latent variables below. Shared variances are reported in the upper half of the matrix. 


\section{Hypothesis Testing}

We use SmartPLS 2.0 and perform its non-parametric bootstrapping algorithm with 1000 resamples to test the model and the causal relationships for statistical significance (Chin 1998; Hair, Ringle, and Sarstedt 2011). Relationship length in years, number of relationship problems, and interdependence are added as control variables. According to Cohen (1988), the variance explained in complacency (16\%), myopia (27\%), vulnerability (16\%), suspicion (28\%), and attractiveness of alternatives (26\%) indicate medium-to-large effect sizes. The Goodness of Fit for the model is .40 , which is acceptable-to-good since it is above the recommended .35 threshold for large effect size models (Tenenhaus et al. 2005).

Overall, we can confirm some of our conjectures. There is no significant relationship between "Re-Evaluation" ( $\left.\beta_{\mathrm{H} 1}=-.06, \mathrm{p}>.10\right)$ and complacency, hence rejecting $\mathrm{H}_{1}$. Screening "Exit Options" has a negative effect on complacency $\left(\beta_{\mathrm{H} 2}=-.18, \mathrm{p}<.05, f^{2}=.03\right)$ supporting $\mathrm{H}_{2}$. The effect of the implantation of "Collective Structures" on complacency is insignificant $\left(\beta_{\mathrm{H} 3}=.04, \mathrm{p}>.10\right)$, thus rejecting $\mathrm{H}_{3}$. There is a positive effect of communicating "Dedicated Assets" on complacency $\left(\beta_{\mathrm{H} 4}=.15, \mathrm{p}<.05, f^{2}=.02\right)$, hence rejecting $\mathrm{H}_{4}$. "Goal Specificity" has a negative effect on complacency $\left(\beta_{\mathrm{H} 5}=-.26, \mathrm{p}<.01, f^{2}=.05\right)$ in support of $\mathrm{H}_{5}$. Complacency relates positively and significantly to myopia $\left(\beta_{\mathrm{H} 6}=.49, \mathrm{p}<.01\right)$, vulnerability $\left(\beta_{\mathrm{H} 7}=.32, \mathrm{p}<.01\right)$, and suspicion $\left(\beta_{\mathrm{H} 8}=.25, \mathrm{p}<.01\right)$, supporting $\mathrm{H}_{6}, \mathrm{H}_{7}$, and $\mathrm{H}_{8}$. To formally test the mediation of complacency between our independent variables and these three symptoms, we conduct three incremental F-Tests which reveal that a simple main effects model cannot outperform our model in terms of variance explained at a 5\% significance level. Second, we perform the Sobel test (Sobel 1987). Specifically, we compute the indirect effect of $\mathrm{X}$ on $\mathrm{Y}$ through $\mathrm{M}$ and compute the ratio of this product to its estimated standard error. Because the assumption of normality of the sampling distribution of the total 
and the indirect effect might be doubtful, we bootstrapped all indirect effects with 1000 resamples (Preacher and Hayes 2008; Shrout and Bolger 2002). Three significant propositions relate to three outcome variables. The Sobel test is significant for six out of these nine relationships at a 5\% level (one-tailed). Specifically, mediation holds for screening exit options ( $\mathrm{z}=1.72$ for myopia; $\mathrm{z}=1.70$ for suspicion; $\mathrm{z}=1.85$ for vulnerability), and for specifying goals $(\mathrm{z}=2.92$ for myopia; $\mathrm{z}=2.25$ for suspicion; $\mathrm{z}=2.19$ for vulnerability), but not for communicating dedicated assets.

A focus on the right side of the model reveals that vulnerability $\left(\beta_{\mathrm{H} 9 \mathrm{~b}}=.27, \mathrm{p}<.01, f^{2}\right.$ $=.08)$ and suspicion $\left(\beta_{\mathrm{H} 9 \mathrm{c}}=.33, \mathrm{p}<.01, f^{2}=.10\right)$ positively relate to the attractiveness of alternatives meaning that the more vulnerable or suspicious partners feel, the more attractive become outside relationship substitutes. Myopia $\left(\beta_{\mathrm{H} 9 \mathrm{a}}=-.18, \mathrm{p}<.01, f^{2}=.04\right)$, however, is negatively associated with the attractiveness of alternatives. We then add the variable "Sunk Costs" to check for interaction effects between the dark side constructs and the attractiveness of alternatives. Its inclusion leads to a significant $\mathrm{R}^{2}$ increase of $\Delta .04$. Its main effect on attractiveness of alternatives is negative $\left(\beta_{\text {SunkCosts }}=-.17, p<.05\right)$ and high levels of sunk costs pronounce $\left(\beta_{\mathrm{H} 10 \mathrm{a}}=-.15, \mathrm{p}<.05\right)$ the negative effect between myopia and attractiveness of alternatives. So high sunk costs promote the attractiveness of the current supplier and they promote staying inside the relationship. The moderation effects between sunk costs and vulnerability $\left(\mathrm{H}_{10 \mathrm{~b}}\right)$ and suspicion $\left(\mathrm{H}_{10 \mathrm{c}}\right)$ are insignificant. 
FIGURE 1

Structural Model

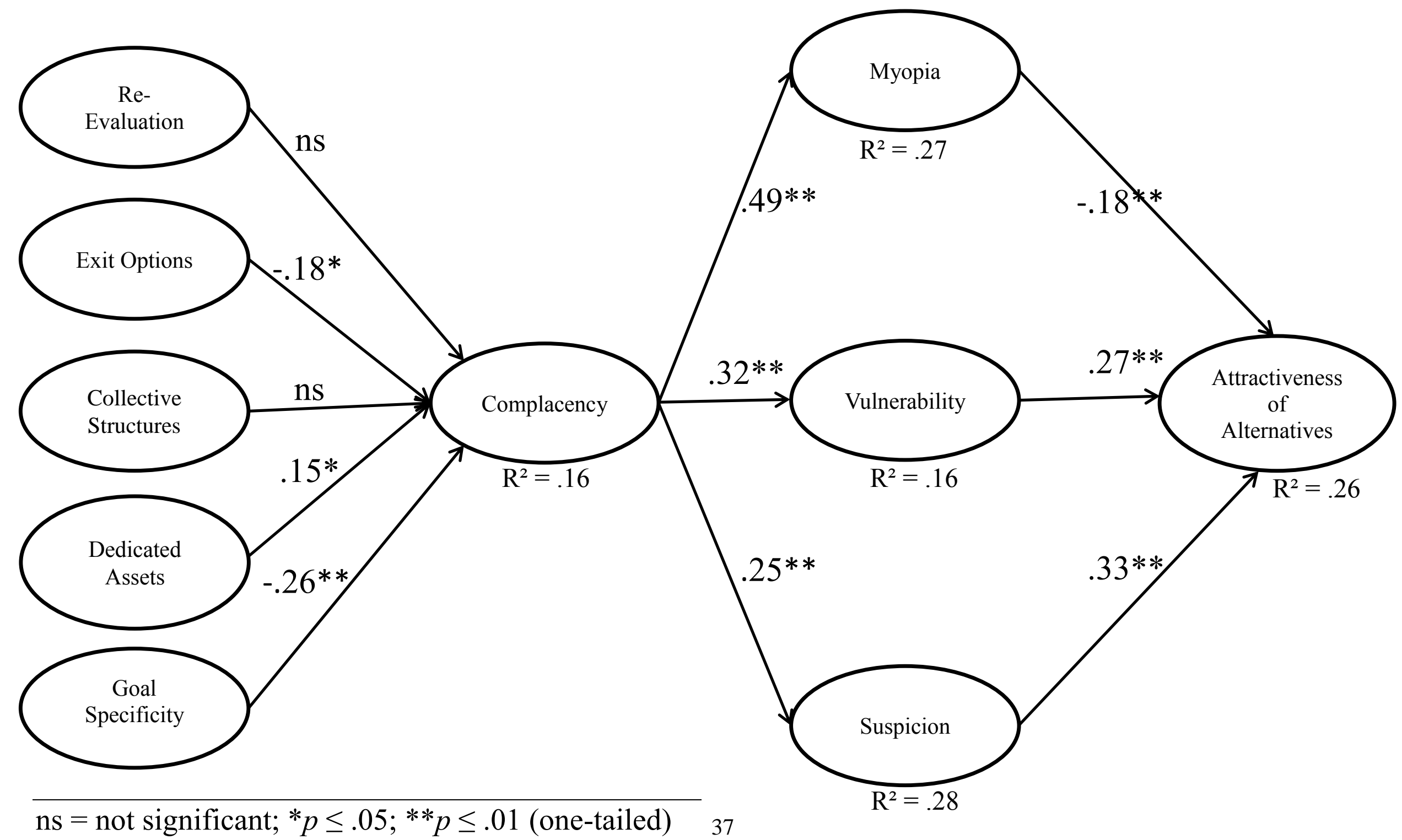




\section{Discussion}

\section{Theoretical Implications}

The results of the study extend our knowledge on B2B relationships in several compelling ways. In essence, we make three significant contributions to the literature. First, we offer more insights about what constitutes these subtle forces that can cause relationship slack or even destruction (Anderson and Jap 2005; Hibbard et al. 2001; Pressey and Tzokas 2004). To this end, we point to the new phenomenon of buyer complacency, which has received little attention so far in the context of the dark side literature (Baker 2009; Scheer 2012). Traditional considerations about "demanding customers" (Boyd and Helms 2005; Thibaut and Kelley 1959) are complemented with theoretical derivations from ergonomics to introduce and define the construct in a relationship marketing context (Moray and Inagaki 2000; Parasuraman, Molloy, and Singh 1993). That way, we provide a rationale for why buyers become unvigilant over time, risking a decline in relationship health.

As a second contribution, theoretical insights follow from illuminating the consequences of buyer complacency on other subsequent dark side symptoms. Complacency nurtures feelings of vulnerability, suspicion, and myopia, so we empirically support earlier assertions that complacency is a subtle relationship destabilizer (Anderson and Narus 1991). Traditionally, trust reduces vulnerability and heightens relationship continuity (Berry 1995). Hence, the positive relationships between complacency and the other subsequent symptoms demonstrate the costs incurred by excessive trust and relational coziness (Stevens, Holweg, and Pil 2012). While complacency enhances these three sentiments, it seems that primarily vulnerability and suspicion foster the search for alternatives to the current relationship. We note particularly low levels of buyers' perceived vulnerability, perhaps because buyers avoid admitting to psychological vulnerability. Denial of vulnerability is common if costs of 
problem and fault identification are high, or when objective vulnerability does not align with self-perceptions of vulnerability (Pechmann et al. 2011). Paradoxically, myopia seems to actually foster a more "locked-in" effect within the relationship. Specifically, an increase in myopia leads to a gradual decrease in the attractiveness of alternative partnerships. Interestingly, in this way a negative symptom - being over-attached to relational routines and having a relational "tunnel-vision" - cements the status quo, delaying or preventing relationship dissolution. Perhaps, partners are temporarily too inflexible to foster neither relationship innovation nor dissolution, so that closeness fosters resistance to innovation (Terawatanavong et al. 2011), or impedes relational learning and performance (Selnes and Sallis 2003). To summarize, this is a first attempt to describe how buyers step into the dark side, and consider the interplay among different symptoms in line with the second contribution of the paper. Our empirical analysis reveals relatively low levels of the four symptoms, confirming previous conjectures about the subtleness of the dark side (Anderson and Jap 2005).

A third contribution was to explore and assess what strategies can be used to minimize the occurrence of complacency. As long term relationships between buyers and suppliers become even more of the norm in the business world (Elmuti and Kathawala 2001), an answer to such a question is paramount for the continued benefit and relevance of relationship marketing. To this end, we are the first to uncover several important conceptual relationships. Among the strategies proposed, "Goal Specificity" seems to keep the dark side at bay because outlining clear duties makes it easier to evaluate performance. This evaluation effect prevents that partners fall asleep, loaf, and cherish the status quo (Harkins and Jackson 1985). Especially under dynamic market conditions, goals make people exert higher effort in controlling and monitoring performance, so that partners constantly learn, adjust, and stay market-oriented, which is a natural antithesis to complacent behavior (Fang, Palmatier, and 
Evans 2004; Hanvanich, Sivakumar, and Hult 2006). Following a similar argument, the screening of potential substitute firms arrests buyer complacency. While such screening acts could create tensions and suspicion in the first place, they guarantee the survival and competitiveness of the partnership (Dant and Gleiberman 2011).

"Re-Evaluation" and "Collective Structures" were shown to be insignificant in their propensity to be worthwhile suppressor strategies. One logical rationale for this finding might be that managers are incapable of objectively evaluating each other, especially given the context of a long term relationship (Moorman, Zaltman, and Deshpande 1992). Additionally, the idea of a team approach to relationship management might be unappealing to buyers because communication among several buyers and sellers is more costly and potentially inefficient. The findings also corresponds to social loafing theory, because individuals tend to expend more efforts when working individually than working collectively (Karau and Williams 1993). Counter to our hypothesis, the strategy of listing "Dedicated Assets" seems to be counterproductive, perhaps because mutual investments are not fungible and thus difficult to redeploy in other relationships (Anand and Singh 1997). Alternatively, buyers might be afraid that listing mutual assets makes exit barriers more salient, lowering a supplier's motivation to go the extra mile, and thus increasing feelings of comfort and complacency in the current relationship (Boughton, Nowak, and Washburn 1996). Finally, theoretical insights emerge from the finding that high sunk costs amplify the tunnel-vision phenomenon so that searching for alternative trading partners is less likely. High sunk costs probably signal not only dependence, but potentially over-dependence, pronouncing the negative effects of inflexibility in close relationships (Terawatanavong et al. 2011). It also corresponds to the previous finding that listing dedicated assets is ineffective, maybe because high sunk costs increase feelings of comfort and coziness while evaluating a trading partner. 


\section{Managerial Implications}

While close B2B relationships are a source of competitive advantage (Dyer, Kale, and Singh 2004), managers must be aware of the costs lying in the positive notion of closeness. Our data reveal low but positive correlations between relationship length and the four dark side symptoms, supporting that the dark side emerges in ongoing, smoothly functioning partnerships. Thus, we offer measurable symptoms for the integration in relationship dashboards, and explain their underlying psychological processes. After the general discovery of diminishing returns in long-term relationships, managers might now understand the occurrence of progressively weaker returns. To combat increasingly disappointing results, companies could install mechanisms to curb particularly buyer complacency, because some relationship managers tend to "stop watching things" (Laughlin 2007), when feelings of selfsatisfaction and false confidence surface.

The empirical analysis gives managerial guidance on installing such mechanisms which help firms to avoid relational slack. Buyers are advised to constantly screen other existing alternatives to prevent relational inattention. For example, firms could follow multiple versus sole sourcing strategies if possible to benchmark performance and signal relational vigilance to the supplier (Burt, Dobler, and Starling 2003). That way, also the supplier might remain vigilant and competitive, because the supplier receives constant market feedback which defies supplier complacency (Brennan 1997).Vice-versa, a supplier who is proactive in buyer education and feedback-seeking (Beverland, Farrelly, and Woodhatch 2004; Challagalla, Venkatesh, and Kohli 2009), might also prevent buyers from falling asleep at the proverbial wheel due to constant adjustments. Moreover, firms could exchange buyers regularly and rotate them to different positions. Ford, for example, rotates its managers who work with dealers every two years to avoid complacency in those relationships (Anderson and Jap 2005). Other than that, firms could think about the composition of buyer teams to keep the 
darks side at bay. The unit of analysis was individual buyers in our sample, who see little use in installing collective structures to monitor relationship progress. Yet, it might depend on the on exact structure of the team, because employing cross-functional teams is particularly helpful to enhance buyer performance (Chen and Paulraj 2004).

Further managerial insights refer to setting concrete goals over greater time horizons. Firms could devote careful attention to planning, developing key metrics, and setting joint targets. It is interesting to note that joint goal setting and planning is conducive to sustain healthy relationships (Christopher and Jüttner 2000; Parsons 2002; Romano 2003), but it also tends to discourage search efforts for new suppliers (Claycomb and Frankwick 2004). Hence, buyers could sustain relational success by setting specific goals while screening exit options regularly, as we suggested earlier. In conclusion, we make an empirical step forward to give concrete guidance to managers on the manifestation of the dark side, and the viability of potential suppressor strategies. 


\section{Limitations and Avenues for Further Research}

While we are encouraged by the results of our study in terms of its implications for the state of relationship marketing science, we acknowledge several limitations of the current study that offer avenues for further research. One avenue for further research would be to collect dyadic data and retrieve relationship information from both buyer and supplier. Conceptually, our approach to assess and combat the dark side is unidirectional because we focus on the buyer who is in the "relational driver's seat." It would be valuable to measure the symptoms in a two-directional pattern so that not only one partner's level of a variable, be it complacency, is measured but mutual complacency, i.e. relationship complacency is considered. Also, this might limit a potential biased caused by socially desirable answers of buyers when we asked them to admit to symptoms such as vulnerability.

Finally, we believe of most practical and academic interest, would be to see how our proposed suppressive strategies play out as experimental treatments. At its current state, our research has tapped into the efficacy of these strategies by asking buyers which of these they practice. Applying these strategies as treatment options and subsequently testing them in a longitudinal lab or field experiment would be an interesting next step in this research area. 


\section{Conclusion}

Given the inevitable rise of the dark side, this paper has conceptualized and operationalized the dark side and investigated the interrelationships among the dark side constructs. In this vein, it has also examined how the dark side symptoms affect the attractiveness of outside relationship substitutes. While opening a veritable Pandora's Box, it has empirically tested a first set of strategies to suppress the onset of the dark side. 


\section{Appendix A: Table 2, Measures and Items}

\begin{tabular}{|c|c|c|c|c|}
\hline Construct & $\mathbf{C R}$ & AVE & SL & Items \\
\hline $\begin{array}{l}\text { Re-Evaluation, } \\
\text { adapted from }\end{array}$ & .88 & .72 & .75 & $\begin{array}{l}\text { 1. Required periodic updates on the } \\
\text { relationship status. }\end{array}$ \\
\hline \multirow[t]{2}{*}{$\begin{array}{l}\text { Matsuno, Mentzer } \\
\text { and Rentz (2000) }\end{array}$} & & & .85 & $\begin{array}{l}\text { 2. Meetings to re-evaluate the latest } \\
\text { relationship developments. }\end{array}$ \\
\hline & & & .93 & $\begin{array}{l}\text { 3. Organizing scheduled dialogues on sorting } \\
\text { out current relationship issues. }\end{array}$ \\
\hline $\begin{array}{l}\text { Exit Options, } \\
\text { adapted from }\end{array}$ & .89 & .73 & .86 & $\begin{array}{l}\text { 1. Encouraging the exploration of the market } \\
\text { for other partnerships. }\end{array}$ \\
\hline \multirow[t]{2}{*}{$\begin{array}{l}\text { Cannon and Perreault } \\
\text { (1999) }\end{array}$} & & & .90 & $\begin{array}{l}\text { 2. Openly discussing the possibility of forging } \\
\text { partnerships with other businesses. }\end{array}$ \\
\hline & & & .81 & $\begin{array}{l}\text { 3. Signaling to my partner that I may have } \\
\text { identified potential substitute suppliers I can } \\
\text { work with. }\end{array}$ \\
\hline \multirow{3}{*}{$\begin{array}{l}\text { Collective Structures, } \\
\text { adapted from } \\
\text { Hult and Nichols } \\
\text { (1999) }\end{array}$} & .89 & .72 & .82 & $\begin{array}{l}\text { 1. Assigning a team to lead and shape the } \\
\text { relationship course as opposed to an } \\
\text { individul manager }\end{array}$ \\
\hline & & & .98 & $\begin{array}{l}\text { 2. Making joint and not individual efforts to } \\
\text { make relationship decisions. }\end{array}$ \\
\hline & & & .74 & $\begin{array}{l}\text { 3. Developing a team orientation in dealing } \\
\text { with supplier issues. }\end{array}$ \\
\hline $\begin{array}{l}\text { Dedicated Assets, } \\
\text { adapted from }\end{array}$ & .92 & .80 & .83 & $\begin{array}{l}\text { 1. Sharing reports on how each party has } \\
\text { dedicated itself to the relationship. }\end{array}$ \\
\hline \multirow[t]{2}{*}{ Nielson (1996) } & & & .93 & $\begin{array}{l}\text { 2. Sending written updates on relationship } \\
\text { investments to each other. }\end{array}$ \\
\hline & & & .93 & $\begin{array}{l}\text { 3. Listing investments each party has made } \\
\text { into the relationship. }\end{array}$ \\
\hline $\begin{array}{l}\text { Goal Specificity, } \\
\text { adapted from }\end{array}$ & .84 & .63 & .80 & $\begin{array}{l}\text { 1. Communicating roles, obligations, and } \\
\text { intentions of each party. }\end{array}$ \\
\hline $\begin{array}{l}\text { Wuyts and Geyskens } \\
\text { (2005); Fang, }\end{array}$ & & & .79 & $\begin{array}{l}\text { 2. Creating a contract that explicitly states } \\
\text { each parties' responsibilities. }\end{array}$ \\
\hline $\begin{array}{l}\text { Palmatier, and Evans } \\
\text { (2004) }\end{array}$ & & & .79 & $\begin{array}{l}\text { 3. Developing a written document that } \\
\text { specifies each parties' expected duties. }\end{array}$ \\
\hline \multirow[t]{2}{*}{ Complacency } & .87 & .69 & .87 & $\begin{array}{l}\text { 1. I have not been careful about financial } \\
\text { implications of this supplier's actions. }\end{array}$ \\
\hline & & & .69 & $\begin{array}{l}\text { 2. My trust in this supplier has made me } \\
\text { ignore future implications of this supplier's } \\
\text { actions. } \\
\text { 3. After I got used to this supplier, I have } \\
\text { stopped thinking about switching suppliers. }\end{array}$ \\
\hline $\begin{array}{l}\text { Myopia, adapted } \\
\text { from }\end{array}$ & .87 & .68 & .83 & $\begin{array}{l}\text { 1. When it comes to this established } \\
\text { relationship, I prefer to stick with things that I }\end{array}$ \\
\hline Baker (2009); Craig & & & & know to work. \\
\hline $\begin{array}{l}\text { and Ginter } \\
\quad(1975)\end{array}$ & & & .87 & $\begin{array}{l}\text { 2. When it comes to this established } \\
\text { relationship, I prefer not to change things that }\end{array}$ \\
\hline
\end{tabular}




\begin{tabular}{|c|c|c|c|c|}
\hline & & & .78 & $\begin{array}{l}\text { have proven to work. } \\
\text { 3. When it comes to how this relationship } \\
\text { operates, I am over-attached to the } \\
\text { conventional ways of doing things. }\end{array}$ \\
\hline $\begin{array}{l}\text { Vulnerability, } \\
\text { adapted from }\end{array}$ & .92 & .79 & .88 & $\begin{array}{l}\text { 1. It seems as though I am helpless when } \\
\text { dealing with this supplier. }\end{array}$ \\
\hline Pearlin et al. (1981) & & & $\begin{array}{l}.92 \\
.86\end{array}$ & $\begin{array}{l}\text { 2. It seems as though the relationship with this } \\
\text { supplier has left us defenseless. } \\
\text { 3. It would appear that I am powerless to } \\
\text { prevent harmful actions of this supplier. }\end{array}$ \\
\hline $\begin{array}{l}\text { Suspicion, adapted } \\
\text { from }\end{array}$ & .91 & .66 & .81 & $\begin{array}{l}\text { 1. I believe that this supplier, at times, acts in } \\
\text { ways that could be harmful to our firm. }\end{array}$ \\
\hline $\begin{array}{l}\text { Baker (2009); Levine } \\
\text { and }\end{array}$ & & & .80 & $\begin{array}{l}\text { 2. I believe this supplier, at times, uses our } \\
\text { relationship against me for its own gain. }\end{array}$ \\
\hline McCornack(1991) & & & $\begin{array}{l}.79 \\
.84 \\
.82\end{array}$ & $\begin{array}{l}\text { 3. I do not believe that this supplier always } \\
\text { accurately reveals its true intentions. } \\
\text { 4. It seems as if this supplier tries to hide } \\
\text { important information from me. } \\
\text { 5. It does not seem that this supplier is } \\
\text { completely truthful in dealing with me. }\end{array}$ \\
\hline $\begin{array}{l}\text { Attractiveness of } \\
\text { Alternatives, } \\
\text { adapted from }\end{array}$ & .91 & .77 & & $\begin{array}{l}\text { Comparing this supplier to others that supply } \\
\text { similar products/services, I find this supplier } \\
\text { to be delivering: }\end{array}$ \\
\hline $\begin{array}{l}\text { Anderson and Narus } \\
\qquad(1984)\end{array}$ & & & $\begin{array}{l}.90 \\
.87 \\
.86\end{array}$ & $\begin{array}{l}\text { 1. Better products/services. } \\
\text { 2. Better sales support services. } \\
\text { 3. Higher market reputation. }\end{array}$ \\
\hline $\begin{array}{l}\text { Note: } \mathrm{CR}=\text { Composi } \\
\text { Loading; items are } \mathrm{m} \\
\text { point, and } 7 \text { indicates }\end{array}$ & rec & & & $\begin{array}{l}\text { rage Variance Extracted, SL }=\text { Standardized } \\
1 \text { indicates "totally disagree", } 4 \text { is the neutral }\end{array}$ \\
\hline
\end{tabular}




\section{Chapter 3}

When Consumers Lose that Lovin' Feeling: Planned Experience

Interventions to Emotionally Recharge Consumer-Brand Relationships 


\section{Introduction}

Many durable goods manufacturers, such as those in the auto industry, spend millions to build and sustain emotional connections with customers (Baker 2011). Yet, consumers lose emotional connections with products over time (Nicolao, Irwin, and Goodman 2009); similarly, they might lose their emotional connections to brands. As a preemptive response to an emotional alienation and its threats to brand loyalty, some car manufacturers offer planned experience days in an attempt to reinvigorate consumer-brand relationships: Jeep invites customers who have owned their vehicles for more than three years to drive cars in challenging off-road settings to reestablish their connection to the brand and encourage new purchases (Auto Editors of Consumer Guide 2011).

Beyond anecdotal evidence though (McAlexander, Schouten, and Koenig 2002), it remains unclear whether or to what extent such experience interventions affect consumerbrand relationships or pay off for companies (Bentenrieder et al. 2011). The returns may be equivocal, especially because practitioners struggle to understand customers' emotional patterns and design planned experiences of the appropriate duration and intensity (Heiman 2010). General Motors first offered planned experiences of one to three days (Kim and Morris 2007), but the company later terminated over-night experience campaigns, due to doubts about their effectiveness for increasing corporate value (Heiman 2010). To fill in this unsolved puzzle, we attempt to shed more light on the extent and temporal pattern of potential affective declines in consumer-brand relationships. In turn, we detail the effectiveness and designs of planned experience interventions that might defuse this emotional alienation.

In previous research, hedonic adaptation theory often provides the basis for explaining temporal declines in consumers' emotions toward products and appropriate ways to intervene (Frederick and Loewenstein 1999; Nicolao, Irwin, and Goodman 2009). Yet, this research 
focuses on discrete product acquisitions (Wang, Novemsky, and Dhar 2009) or short-term consumption experiences (Nelson and Meyvis 2008), without addressing whether the findings extend to brands or to planned experiences for managing consumer-brand relationships over longer time horizons. Despite some emphasis on the pivotal role of emotional attachment for establishing lasting consumer-brand relationships (Park et al. 2010), little academic attention has considered hedonic brand adaptation or mechanisms for addressing it (He and Chen 2011). Hence, we aim to contribute to literature on hedonic brand adaptation by investigating whether and how planned experiences might defuse its effects.

First, we monitor how emotional patterns develop over time in progressive consumerbrand relationships to illuminate the emotional decline problem. We verify the erosion of positive brand affect and thereby extend research on brand attachment while responding to recent calls for empirical evidence about the "temporal development—and possible waning — of brand affections" (Batra, Ahuvia, and Bagozzi 2012, p. 14). Second, we draw on affectsustaining interventions from psychology literature (Lyubomirsky, Sheldon, and Schkade 2005; Mochon, Norton, and Ariely 2007) to propose planned experiences as an intervention mechanism that can prevent hedonic adaptation effects in a relational setting. With this suggestion, we contribute to knowledge on the effectiveness of planned experiences, defined as an event for consumers to receive direct emotional stimulation from multi-sensory activities to nurture brand affect. Yim, Tse, and Chan (2008, p. 753) argue that "we cannot expect such relationships to take care of themselves, any more than we can expect that of interpersonal relationships. Rather, firms must strive to make affectionate relationships with customers the best they can be". Accordingly, we test and analyze the consequences of this intervention mechanism on customer loyalty. Third, we explore the repercussions of designing planned experiences with varying emotional intensity. Previous literature highlights the role of natural breaks to intensify positive consumption experiences (Nelson and Meyvis 
2008); we distinguish between continuous and disrupted experiences to design low and high intensity interventions. These two intervention types differ in their potential to forestall an emotional decline, so we offer insights into efficient designs of the intervention mechanism.

In the next section, we review literature on hedonic adaptation, including current mechanisms to defuse it. We then propose planned experiences as novel intervention mechanisms to influence adaptation dynamics in progressive consumer-brand relationships. In a longitudinal field experiment and a laboratory experiment, we test our conjectures, which reveal some key implications for academics and practitioners. 


\section{Theoretical Framework}

\section{Hedonic Adaptation Theory}

Prior literature in both marketing and psychology has addressed the process of hedonic adaptation, or the emotional attenuation of an experience over time (Frederick and Loewenstein 1999). Positive (consumption) experiences become less positive, and negative (consumption) experiences become less negative over time (Nicolao, Irwin, and Goodman 2009). People adapt quickly to pleasurable experiences such as earning tenure (Gilbert et al. 1998), getting married (Lucas and Clark 2006), or winning the lottery (Brickman, Coates, and Janoff-Bulman 1978). Such temporal attenuation likely results from psychological and physiological mechanisms that foster coping and habituation as means to protect emotional systems, which cannot operate properly under continuously arousing settings (Lyubomirsky et al. 2011). In addition, positive experiences change peoples' reference points for successive experiences, so subsequent affective reactions must strongly differ from the established level to be noticeable. The question thus becomes how companies can overcome such an emotional decline to maintain affect-based customer loyalty over time (Yim, Tse, and Chan 2008).

\section{Counteracting Hedonic Adaptation}

Improving affective forecasting. Consumers need support to predict their adaptation accurately, because they generally hold inaccurate beliefs about their hedonic adaptation to specific items (Wilson, 2000). Because they are notoriously bad at predicting their product enjoyment for goods consumed over time, shaping correct beliefs among consumers about their affect progression, prior to the purchase, may alter their post-usage evaluations (Patrick, MacInnis, and Park 2007), likely for the better (Wang, Novemsky, and Dhar 2009). However, efforts to support consumers' affective forecasting are inherently limited to the pre-purchase 
stage and ignore any opportunities to take corrective measures during or after multiple consumption experiences, when the hedonic downturn actually occurs. Because consumers expect ongoing value from brand relationships, improving affective forecasting just on the product level might not change their accumulated brand experiences (Erdem, Swait, and Valenzuela 2005; Fournier 1998).

Inserting breaks. To counteract the affective downward trend in positive consumption experiences, Nelson and Meyvis (2008) suggest inserting breaks. Breaks disrupt the adaptation process and then intensify experiences and pleasure after the pause. In a series of laboratory experiments, they find empirical support for their claim that breaks make positive, discrete service experiences more enjoyable. Yet, we do not know if the findings also transfer to the continuous consumption of durable goods. Our study addresses this gap.

Affect-sustaining interventions. Lyubomirsky, Sheldon and Schkade (2005) find that approximately half of the variance in people's well-being depends on a preset biological happiness point (i.e., genetic), 10\% on individual life circumstances (e.g., income level, marital status), and up to $40 \%$ on positive, happiness-enhancing activities (e.g., exercising, spending extra time socializing) ${ }^{1}$. Thus, positive mental or behavioral interventions are promising, because they "may serve as a natural antidote to the process of hedonic adaptation" (Lyubomirsky et al. 2011, p. 392). Studies have documented longer-lasting effects when participants engaged in daily happiness-enhancing activities over a six-week time

\footnotetext{
${ }^{1}$ We use the term "happiness" as an umbrella reference to related constructs, such as infrequent negative affect or frequent positive affect. These primary components relate to a single underlying factor (Lyubomirsky, Sheldon, and Schkade 2005), and happiness is often used in current marketing discussions of hedonic adaptation to purchases (Nicolao, Irwin, and Goodman 2009).
} 
horizon (Fordyce 1983). Seligman and colleagues (2005) report that two simple one-week interventions (i.e., writing down three good things that happened each day and using character strengths in a new way every day) increased participants' happiness levels for more than half a year.

The rationale underlying such interventions is that planned, intentional activities draw people's attention to a new object or circumstance, which renews their appreciation of the ordinary. Engaging in interventions reframes information and prevents people from taking existing features for granted (Lyubomirsky, Sheldon, and Schkade 2005). Following this logic, a long-term Jeep owner might experience renewed appreciation for the brand if he or she consciously creates fresh experiences, such as road tripping with friends or cherishing the brand's features (Lyubomirsky 2011). Because this intervention mechanism seems both conceptually rich and innovative for the context of brand adaptation, we apply it next to derive our hypotheses. 


\section{Hypotheses Development}

\section{Hedonic Adaptation to Brands}

Hedonic adaptation refers to changes in brand- or product-related affective reactions. According to Chaudhuri and Holbrook (2001), brand affect is a positive emotional response from consumers elicited by a brand. Because the brand is an intangible, high-level construal that triggers affective consumer reactions (Trope and Liberman 2010), its influence on consumer behavior might differ from associated affect that stems from a product. A product is more concrete, feature-based, and tangible, with low-level construal, such that product affect is consumers' emotional response triggered by discrete consumption or usage experiences.

In line with hedonic adaptation theory, consumers' affect with a product follows a naturally declining trajectory (Nicolao, Irwin, and Goodman 2009), mainly caused by habituation effects and increased reference points. In general, adaptation seems faster for material goods, such as cars, than for experiential goods, such as vacations (Dunn, Gilbert, and Wilson 2011). Experiential purchases can still be enjoyed in memory and remain open to positive reinterpretations after their consumption (Van Boven 2005).

Brands are intangible and transcendent concepts that emerge from the product, its use, and accompanying marketing activities (Erdem, Swait, and Valenzuela 2005; Keller and Lehmann 2006), and hence, they involve the complete experience that customers undergo. Again following hedonic adaptation theory, we argue that brands lose their power to emotionally arouse customers due to their heightened expectations and habituation to a certain stimulation level. Waning product affect also could influence the temporal patterns of brand affect (Chaudhuri and Holbrook 2001). Finally, brands aim for continuity in their quality signaling capability, which generally requires an unchanging brand appearance (Fischer, 
Völckner, and Sattler 2010). Because brands cannot be continuously renewed or changed, they likely suffer wear-out processes. We propose in turn:

$\mathrm{H}_{1}$ : In the course of a relationship, consumers' brand affect declines.

\section{Planned Experience Interventions to Influence Hedonic Adaptation to Brands}

In response to such potential threats of hedonic adaptation, planned experience interventions aim to reinvigorate or boost consumers' relationships with brands in progressive relationship stages. From a corporate perspective, interventions are "planned" because the firm proactively initiates the event and provides operand resources to nurture brand affect. From a consumer perspective, they are "planned" because consumers' attention is drawn to an event that takes place in the future; hence, they might look forward to such an event and act on these resources to co-create emotional stimulation effects. Using a case-study approach, Zomerdijk and Voss (2010) similarly recommend experience-centric services, for which they find that "customer journeys" are the most effective design of emotionally compelling experiences. Planned experience interventions incorporate this journey, in that they range from an invitation and anticipation to the actual event and then savoring the experience ex post.

Direct consumer stimulation is key for integrating new relationship salience and meaning into a consumer-brand relationship; in line with this, planned experience interventions proactively engage customers in multisensory activities that trigger both attention and bodily interaction to nurture brand emotions, such as hosting a community event or offering exciting test drives.

Psychology literature also offers considerable evidence that discrete interventions can counteract hedonic adaptation (Fordyce 1983; Lyubomirsky, Sheldon, and Schkade 2005; 
Seligman et al. 2005). Our prediction of a positive effect of a planned experience treatment on brand affect is in line with the experience recommendations, because experiences can be enjoyed longer through memory and remain open to optimistic reinterpretations (Van Boven 2005). That is, we anticipate an emotional brand recharge through planned experience interventions:

$\mathrm{H}_{2}$ : Participation in a planned experience intervention has a positive effect on consumers' brand affect.

Beyond the positive hypothesized effect on brand affect, we predict that interventions differ in their relative efficacy. According to Nelson and Meyvis (2008), multiple interrupted experiences should deliver more enjoyment than one continuous experience, because pauses intensify the experience both before and after the break, as consumers anticipate and look forward to restarting the pleasant activity (Loewenstein 1987; Nelson and Meyvis 2008). Thus, people extract more positivity from an intervention if they engage in multiple as opposed to one continuous consumption experience, which matches the prospect theory assertion that people might derive more utility from multiple smaller gains than from one larger gain (Kahneman and Tversky 1979). Major breaks in positive experiences can determine the low-to-high intensity continuum of interventions, and we hypothesize:

$\mathrm{H}_{3}$ : Disrupted interventions have a higher positive effect on consumers' brand affect than continuous interventions.

Regardless of the emotional continuum though, the affective boost on the brand level should relate positively to repurchase behavior. Johnson, Herrmann, and Huber (2006) highlight the central role of affective ties for driving loyalty intentions. Yim, Tse, and Chan 
(2008) consider enduring affectionate ties between the customer and the firm as a key differentiator of "true" loyalty. Thus,

$\mathrm{H}_{4}$ : Increasing brand affect has a positive effect on repurchase probability. 


\section{Research Design and Data}

\section{Field Experiment with Automotive Customers}

Research setting. A natural field experiment was conducted in cooperation with an automotive manufacturer over approximately a two-and-a-half-year period to test our conjectures. There are several benefits of this experimental design and industry setting. First, the sample of existing customers, by definition, made purchasing decisions before participating. These real consumers likely display more accurate valuation or adaptation patterns than respondents who evaluate hypothetical or provided goods in a laboratory study (Pollai, Hoelzl, and Possas 2009). Second, cars are largely hedonic products that elicit high levels of brand affect. This industry setting thus is ideal for capturing the depth of consumers' emotional adaptation patterns to brands. Third, cars are durable goods and accordingly, they are uniquely qualified in discussions of hedonic adaptation in that they deliver utility over greater time horizons. Fourth, because some of the expected effects may be time-variant, such as adaptation and adaptation-defusing developments, we need panel data, and the usage cycles of cars makes this context likely to provide such data.

Experimental sampling and manipulations. The experiment included customers who had bought their last vehicle approximately three years prior $\left(\mathrm{t}_{-1}\right)$. Research on relationship lifecycles for the focal brand has indicated that customers start considering a potential repurchase after approximately three years (Zetu et al. 2003). Therefore, at this point in the lifecycle customers are considering a return to the market and thus are receptive to marketing efforts. Leasing customers as opposed to regular customers do not own the vehicle and thus should experience the adaption process differently (Wang, Novemsky, and Dhar 2009). As a consequence, we consider actual car ownership as the overriding selection criterion and focus on regular customers. Initially $\left(\mathrm{t}_{0}\right), 11,199$ customers were randomly assigned to two 
conditions: $20 \%$ to a non-intervention control group (CG) and $80 \%$ to an experimental condition (EG). Subjects in the EG completed three surveys, approximately one $\left(\mathrm{t}_{1}\right)$, six $\left(\mathrm{t}_{2}\right)$, and twelve $\left(t_{3}\right)$ months after the intervention. The CG did not participate in any experience intervention and completed surveys at similar intervals.

Direct product experiences trigger emotional reactions (Kempf 1999). Besides, Zomerdijk and Voss (2010) recommend customer journeys as particularly effective emotional experiences. A journey runs from customer anticipation and arrival to departure and savoring of the experience ex post. Thus, we followed this concept when designing our intervention. The invitation to a temporally distant event encouraged consumer anticipation and arrival; the take-away material related to the savoring stage. Approximately three years after the last purchase $\left(\mathrm{t}_{0}\right)$, participants in the experimental condition received a personal, mailed invitation to participate in an experience event at the local dealership. Customers could choose either an afternoon or a weekend test drive with a vehicle equal in size to their current car. Additionally, the invitation featured a personal introduction to the car plus conversations before and after the test drive with a frontline employee. Customers that accepted the afternoon test drive were grouped in experimental group one (EG1) and those with the weekend test drive in experimental group two (EG2).

Nelson and Meyvis (2008) further show that inserting breaks in positive consumption experiences increases the intensity of the experience, because consumers anticipate and look forward to restarting the pleasant activity again (Loewenstein 1987; Nelson and Meyvis 2008). Practically, consumers who had the car overnight (EG2) were exposed to these natural breaks while consumers in EG1 were not. Thus, the number of disruptions is manipulated by event duration. 
The manufacturer did not offer the same experience days to other customers except those in EG1 and EG2 during the experimental time period in the focal sales territory, so customers in the control condition were not affected. We also conducted validity checks across all groups; the surveys asked customers whether they had participated in additional dealer-related activities, such as ordinary test drives. In the control group, approximately $30 \%$ of the participants did so, and we controlled for this effect in our analysis.

After they received the invitation, the participants in the experimental groups had several months to comply with the offer. Experience participation was recorded in a database administered by the manufacturer's market intelligence department. We are not interested in the effect of the potential offer on nonparticipants, so the experiment involved contacts only with compliant participants in the experiment, called and surveyed by professional interviewers approximately one month $\left(t_{1}\right)$, six months $\left(t_{2}\right)$, and twelve months $\left(t_{3}\right)$ after the experience. The posttest-only control group design helped exclude potential learning and demand effects of consumption prior to the intervention (Argyris 1968). Roughly one and a half years after the last interview round, or approximately five years after a customer's last purchase, we matched the experimental data related to group membership, experience participation (compliant vs. noncompliant), and telephone interviews, complementing them with account information from the firm's customer relationship management database (e.g., repeat purchase). Given the average inter-purchase time for the car brand considered in this study, the repurchase decision process had ended for the majority of customers after five years, which reduces concerns about a truncation bias in our purchase data (Helsen and Schmittlein 1993). Vice-versa, few customers across groups repurchased a new vehicle relatively early, such as three years after their purchase in $t_{-1}$. Because we are interested in the hedonic trajectories related to the vehicle bought in $t_{0}$, we excluded these respondents to avoid confounding effects. 


\section{Data}

From the initial sample of 11,199 customers, a random assignment process put $20 \%$ in the control condition, and $80 \%$ in the in the experimental condition. Panel mortality decreased the sample of those who complied with the experience offer and those who only answered the survey to 822 respondents in $t_{3}$. We conducted several analyses of variance to check for nonresponse or potential selection biases due to sample attrition. There were no significant differences at a 5\% level between respondents and non-respondents in their demographics or previous customer performance data. Thus, we attained usable panel data for 822 consumers ( $\mathrm{n}=440$ for $\mathrm{CG}, \mathrm{n}=167$ for EG1, and $\mathrm{n}=215$ for EG2).

Survey measures. To operationalize brand affect, we adapted existing affective commitment scales from Fullerton (2005). Three items measured the construct and a typical item was for example "It is pleasant to belong to the brand community" $(1=$ completely disagree, 7 = completely agree). Our scale reliabilities were good for the focal construct; Cronbach's alpha varied between .79 and .83 . Additionally, we included brand and product satisfaction, with seven-point, low to high, single-item measures for each construct. Two bilinguals translated the original measures into the country-specific language and back into English. After minor adjustments, no problems were detected between the original and the back-translated items. Using various Internet search engines and media archives, we detected no critical company events during the experimental period that might have influenced the measurements.

\section{Methodology}

Customers' participation in the two experience interventions represents treatments; we thus examined the temporal effects of these treatments on customers' brand affect and repurchase behavior. Customers self-select into the compliant (by accepting the invitation and 
taking the offer for an afternoon or a weekend) and noncompliant (by refusing the invitation and not taking the offer) groups. Thus, the participants conceivably could differ in their characteristics prior to receiving the treatment, in which case the post-treatment difference (or lack thereof) might be erroneously attributed to a treatment.

To support causal inferences about the true treatment effects though, we cannot simply compare the entire experimental groups with the entire control group (Imbens and Wooldridge 2009). Thus, we apply Propensity Score Matching (PSM), a method often used in economics and social sciences, especially in the context of natural field experiments, to estimate the causal effects of program participation (Lechner 2002; Wangenheim and Bayón 2007). The underlying logic is to select only members of a control group that closely resemble treatment receivers, according to meaningful pre-treatment covariates (Caliendo and Kopeinig 2008). If the pretreatment covariates are exogenous and capture the selection process, which represents the conditional independence assumption, we can calculate a customer's participation probability or propensity score conditional on these covariates (Rosenbaum and Rubin 1983). Matching treatment receivers and their statistical twins on the propensity score thus provides a reasonable method for assessing experience intervention effectiveness. However, the appropriateness of the conditional independence assumption also depends on theoretical arguments, data availability, and empirical insights that have supported the selection process (Lechner 2002).

We turned to the manufacturer's insights as well as previous academic literature about compliance (Wangenheim and Bayón 2007) to determine which demographic variables (e.g., age, gender) and previous customer performance variables (e.g., price of the last vehicle, number of cars per household) might predict program participation. Such variables were available in the manufacturer's database. Additionally, two metric covariates were available: "How important is a test drive for your purchasing decision?" and "How important is [Brand] 
for your purchasing decision?" (seven-point Likert-scale, 1 = "not all important" and $7=$ "very important"). Although we cannot claim that our covariates perfectly satisfy the conditional independence assumption, our knowledge about the selection mechanism and the relatively large set of available covariates plausibly satisfy it. Mealli and Rubin (2003) even show that one or two covariates often are sufficient to predict compliance correctly.

First, we specified two binomial probit models to predict treatment participation based on the observable covariates for each of the two treatments (i.e., continuous intervention EG1 and disrupted intervention EG2; see Table 1). The outcome variable of the model was coded one in case of participation and zero otherwise. The results confirmed our intuition that younger and high-value customers were more likely to comply with the offer.

TABLE 1

Results of Probit Regression Analysis

\begin{tabular}{lcc}
\hline Independent Variable & $\begin{array}{c}\text { Continuous Intervention } \\
\text { (EG1) }\end{array}$ & $\begin{array}{c}\text { Disrupted } \\
\text { Intervention (EG2) }\end{array}$ \\
\hline Constant & $-1.33(.48)^{* * *}$ & $-1.47(.48)^{* * *}$ \\
Age (in years) & $-.16(.05)^{* * *}$ & $-.19(.05)^{* * *}$ \\
Gender $(1=$ male) & $.17(.15)$ & $.34(.09)^{* *}$ \\
Price of current car in $€$ & $.16(.00)^{* *}$ & $.18(.00)^{* *}$ \\
Importance of brand for purchase decision & $-.02(.04)$ & $.04(.04)$ \\
Importance of test drive for purchase decision & $.13(.04)^{* * *}$ & $.16(.03)^{* * *}$ \\
Number of cars purchased in the last 10 years & $.08(.04)^{* *}$ & $.09(.04)^{* *}$ \\
Number of cars per household & & $.09(.05)^{*}$ \\
Size of the current car - small & $.12(.05)^{* *}$ & - \\
Size of the current car - midsize & - & $-.34(.16)^{* *}$ \\
Size of the current car - large & $-.40(.16)^{* *}$ & $-.32(.22)$ \\
Education - low & $-.39(.23)^{*}$ & - \\
Education - middle & - & $-.09(.15)$ \\
Education - high & $.21(.17)$ & $-.26(.16)$ \\
& $.15(.18)$ & -370.65 \\
Log-likelihood & & 71.60 \\
Percentage of cases correctly classified & -327.07 &
\end{tabular}

Notes: The dependent variable is treatment participation $(1=$ treatment; $0=$ otherwise). The coefficient for age is multiplied by 10 . The coefficient for price of the current car is multiplied by 1,000 . The parameter for size of the current car - small is set to 0 . The parameter for education - low is set to 0 .

A third probit model revealed whether compliant respondents in EG1 differed significantly from compliant ones in EG2, but this model was not significant $(p=.60)$. Thus 
the selection mechanism appeared fairly similar across both experimental groups, and in our subsequent analyses, we compare them without applying a selection correction.

Second, we matched the compliant members of each experimental group with a participant in the control group, using the computed propensity scores. Several matching algorithms are available, such as nearest-neighbor or caliper matching (Caliendo and Kopeinig 2008). Although the nearest-neighbor algorithm is intuitive, a nearest neighbor can be far away (Wangenheim and Bayón 2007). To avoid bad matches, we applied caliper matching and specified a tolerance zone $\varepsilon$ to set a maximum distance between two propensity scores (Silverman 1986). We thus identified adequate matching partners from the control group $(n=440)$ for $97.6 \%$ of the original EG1 group $(n=163)$ and $83.7 \%$ of the EG2 group $(\mathrm{n}=180)$.

Third, to assess matching quality, we checked for significant differences in the covariate means, after matching the experimental groups with a statistical twin (Leuven and Sianesi 2003). Ideally, the previously significant differences in means between an experimental and a control group should vanish after matching. As Table 2 shows, all eleven covariates were insignificant after matching both models, which increases our confidence in the similarity of the experimental and control groups. We also inspected the percentage reduction in bias (PRB) and found acceptable to high quotas for all the covariates (Rosenbaum and Rubin 1984). Next we re-estimated the probit models with the matched sample; as we expected, all covariates in the probit models were balanced, with an insignificant joint effect. With these quality checks, we found no systematic differences, and the treatment effects appeared independent of participants' self-selection.

Fourth, we conducted repeated measures (RM) ANOVAs with our matched samples (CG1 EG1, CG2 EG2, and EG1 EG2) to inspect the treatment effects over the three points in 
time on brand affect (Maxham and Netemeyer 2002). This method allows inspecting (1) the within-subjects effect of time; (2) the between-subjects effect of group membership; and (3) the interaction between group membership and time, to determine if groups follow the same patterns over time.

TABLE 2

Covariate Means of Groups Before and After Matching and Percentage Reduction in Bias

\begin{tabular}{|c|c|c|c|c|c|c|}
\hline \multicolumn{3}{|r|}{ Before Matching } & \multicolumn{4}{|c|}{ After Matching } \\
\hline CG1 & EG1 & Continuous Intervention $(n=163)$ & CG1 & EG1 & $p>|t|$ & PRB \\
\hline 54.13 & 48.94 & Age & 49.32 & 49.08 & $85.7 \%$ & $95.4 \%$ \\
\hline 78.86 & 80.24 & $\%$ male customers & 78.52 & 79.76 & $78.6 \%$ & $10.8 \%$ \\
\hline$*$ & $*$ & Price of current car in $€$ & * & * & $73.2 \%$ & $81.4 \%$ \\
\hline 5.45 & 5.37 & Importance of brand for purchase decision & 5.20 & 5.36 & $34.9 \%$ & $-81.0 \%$ \\
\hline 5.28 & 5.88 & Importance of test drive for purchase decision & 5.98 & 5.86 & $44.5 \%$ & $79.5 \%$ \\
\hline 2.20 & 2.53 & Number of cars purchased in the last 10 years & 2.47 & 2.51 & $83.4 \%$ & $87.2 \%$ \\
\hline 1.92 & 2.31 & Number of cars per household & 2.22 & 2.24 & $83.4 \%$ & $93.6 \%$ \\
\hline 53.41 & 41.91 & $\%$ current car (midsize) & 38.04 & 42.94 & $36.8 \%$ & $57.3 \%$ \\
\hline 27.50 & 33.53 & $\%$ current car (large) & 33.74 & 31.90 & $72.4 \%$ & $69.5 \%$ \\
\hline 50.0 & 59.88 & $\%$ education (middle) & 60.12 & 59.50 & $91.0 \%$ & $93.8 \%$ \\
\hline 30.68 & 28.14 & $\%$ education (high) & 28.83 & 28.21 & $90.3 \%$ & $75.8 \%$ \\
\hline $\mathrm{CG} 2$ & EG2 & Disrupted Intervention $(\mathrm{n}=180)$ & CG2 & EG2 & $\mathrm{p}>|\mathrm{t}|$ & PRB \\
\hline 54.13 & 48.54 & Age & 48.43 & 49.94 & $23.4 \%$ & $73.2 \%$ \\
\hline 78.86 & 84.19 & $\%$ male customers & 82.22 & 81.11 & $78.6 \%$ & $79.1 \%$ \\
\hline$*$ & * & Price of current car in $€$ & * & * & $61.9 \%$ & $74.3 \%$ \\
\hline 5.45 & 5.59 & Importance of brand for purchase decision & 5.42 & 5.54 & $41.2 \%$ & $13.1 \%$ \\
\hline 5.28 & 6.09 & Importance of test drive for purchase decision & 5.96 & 5.95 & $97.2 \%$ & $99.3 \%$ \\
\hline 2.20 & 2.53 & Number of cars purchased in the last 10 years & 2.34 & 2.36 & $95.0 \%$ & $96.7 \%$ \\
\hline 1.92 & 2.27 & Number of cars per household & 2.06 & 2.14 & $51.4 \%$ & $77.9 \%$ \\
\hline 53.41 & 41.40 & $\%$ current car (midsize) & 45.56 & 46.11 & $91.6 \%$ & $95.4 \%$ \\
\hline 27.50 & 33.02 & $\%$ current car (large) & 30.56 & 29.44 & $81.9 \%$ & $79.9 \%$ \\
\hline 50.0 & 55.81 & $\%$ education (middle) & 55.0 & 57.22 & $67.2 \%$ & $61.8 \%$ \\
\hline 30.68 & 24.65 & $\%$ education (high) & 26.67 & 24.44 & $63.0 \%$ & $63.2 \%$ \\
\hline
\end{tabular}

Notes: $97.6 \%$ of original respondents matched for the EG1 group, and $83.7 \%$ for the EG2 group. PRB = percentage reduction in bias.

*Omitted for confidentiality reasons. 


\section{Results}

\section{Hypotheses Tests}

In line with Sloot, Fok, and Verhoef (2006), we classified any effects up to six months after the treatment as short-term and those detected afterward as long-term effects. That is, measurements in $t_{1}$ and $t_{2}$ refer to the short-term, and those in $t_{3}$ involve long-term effects. To test $\mathrm{H}_{1}-\mathrm{H}_{3}$, we conduct three multi-way RM ANOVAs for each sample, with time as the within-subject factor (i.e., $t_{1}, t_{2}, t_{3}$ ) and the sample-specific manipulation group as the between-subject factor (i.e., CG1 vs. EG1, CG2 vs. EG2, EG1 vs. EG2). We also included interaction terms between the time and group membership factors to determine if groups followed (dis)similar patterns over time. The two CGs differ in their composition and potentially in their affective trajectories because the matching procedure selected statistical twins from the overall $\mathrm{CG}$ according to the respective experimental group. Compared to the CG1 EG1 and the CG2 EG2 sample, the comparison of the two experimental groups (EG1 EG2) contained slightly more treatment receivers that were removed from the other samples to increase the matching quality.

For the within-subjects analysis in the CG1 EG1 sample, the effect of time on brand affect was significant $\left(\mathrm{F}_{\mathrm{GG}}(1.88,606.5)=3.43, p<.05\right)^{2}$. Brand affect parallels an almost linear decline for both groups over time. The CG2 EG2 sample revealed a short term decline in brand affect for the EG and a long-term decline for the $\mathrm{CG}$ over time $\left(\mathrm{F}_{\mathrm{GG}}(1.94,691.1)=\right.$ $4.12, p<.05)$. Similarly, the third sample (EG1 EG2) showed a decreasing trajectory of brand

\footnotetext{
${ }^{2}$ We applied a Greenhouse-Geisser correction to the degrees of freedom, in case the assumption of sphericity was violated -indicated as GG subscript to the F statistic if applicable.
} 
affect that stabilized in the long run $(\mathrm{F}(2,760)=3.53, p<.05)$. Because the downward trend held in the short-term but faded out for the EGs in the long-term, we find partial support for $\mathrm{H}_{1}$ (see Figure 1).

FIGURE 1

Trajectory Brand Affect for CG1 EG1 Sample (Continuous Intervention)

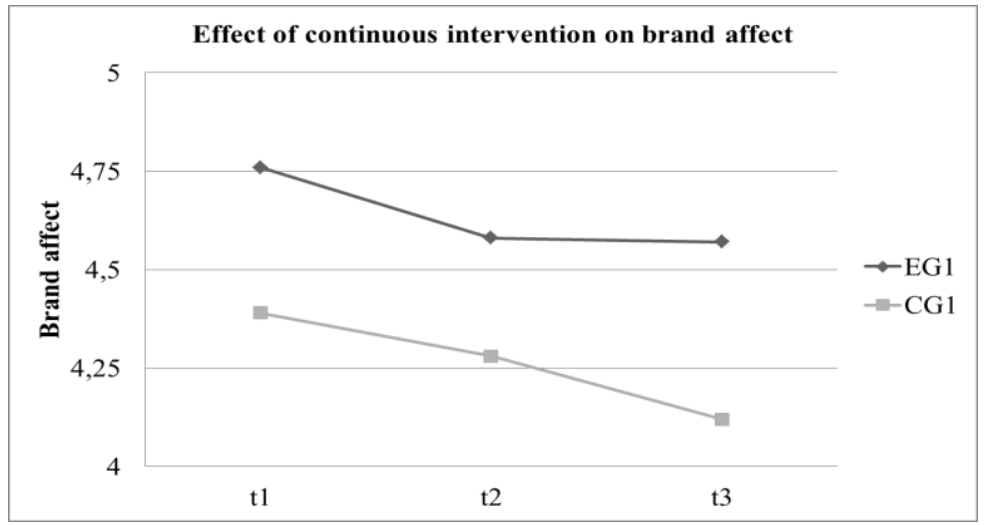

Trajectory Brand Affect for CG2 EG2 Sample (Disrupted Intervention)

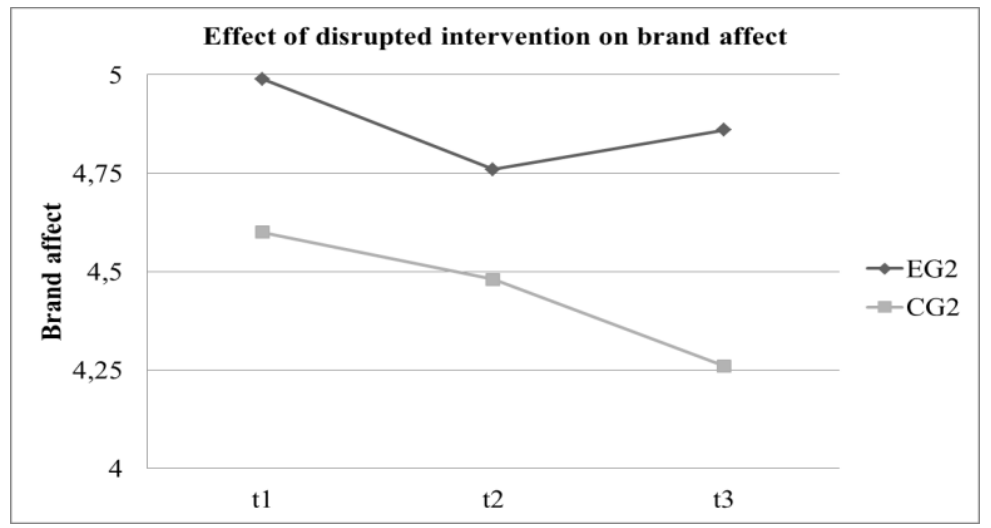

Trajectory Brand Affect for EG1 EG2 Sample (Continuous and Disrupted Intervention)

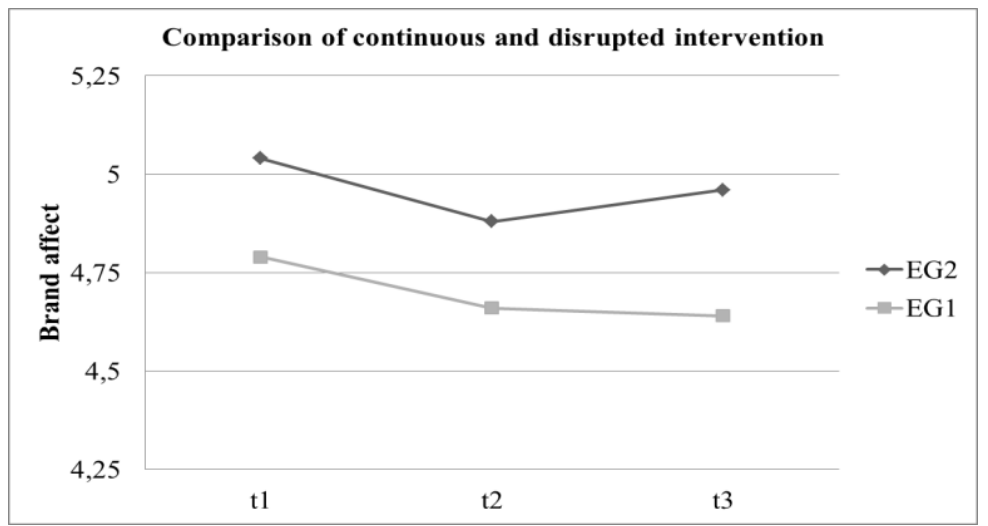


For the between-subjects analysis, the effect of the intervention was significant for the continuous intervention $(\mathrm{F}(1,323)=5.23, \mathrm{M} \Delta=.38, p<.05)$ and for the disrupted intervention $(\mathrm{F}(1,357)=7.88, \mathrm{M} \Delta=.43, p<.01)$ in support of $\mathrm{H}_{2}$. That is, in both experimental groups, the time-averaged means for brand affect were higher than in the control groups. We predicted that disrupted interventions would result in higher levels of brand affect than continuous interventions, and the between-subjects effect for the two experimental groups was significant and in the expected direction $(\mathrm{F}(1,380)=4.40, \mathrm{M} \Delta=.27, p<.05)$, in support of $\mathrm{H}_{3}$.

Next, we predicted high levels of brand affect might heighten repurchase probability $\left(\mathrm{H}_{4}\right)$. As the dependent variable for this analysis, we used customers' repurchase of the current brand $(0=$ no, $1=$ yes $)$. As independent variables, we used brand affect along with brand and product satisfaction as more cognitive counterparts. The independent variables featured panel data from three waves, whereas the outcome variable was discrete, so we estimated for each sample a pooled logistic regression to correct for error correlation within participants over time (Wooldridge 2009). We started by testing the main effects, and then added interaction effects. However, none of the models improved with the inclusion of interaction terms, so we report the most parsimonious solution in Table 3.

Across the three samples, brand affect offered a significant, positive predictor of repurchase rate. Converting the coefficients into odd ratios indicated that a one-point increase in brand affect heightened the probability of repurchase by a factor of 1.21 (CG1 EG1 sample), 1.38 (CG2 EG2 sample), and 1.26 (EG1 EG2 sample). Thus, brand affect drives behavioral loyalty, in support of $\mathrm{H}_{4}$. 
TABLE 3

Results of Logit Model (with Panel-robust Standard Errors)

\begin{tabular}{llll}
\hline \multicolumn{3}{c}{ Dependent Variable: Repurchase } \\
\hline $\begin{array}{l}\text { Independent } \\
\text { Variables }\end{array}$ & CG1 EG1 (a) & Sample & \\
\hline Constant & $-4.58(.65) * * *$ & $-6.17(.65) * * *$ & EG1 EG2 (c) \\
Brand affect & $.19(.08) * * *$ & $.32(.05) * * *$ & $-2.45(.49) * * *$ \\
Brand satisfaction & $.31(.10) * * *$ & $.38(.10) * * *$ & $.23(.05) * * *$ \\
Product satisfaction & $.20(.10) * *$ & $.31(.10) * * *$ & $.12(.09)$ \\
\hline Wald $\chi^{2}$ & 63.41 & 142.09 & $.08(.09)$ \\
Pseudo Log-likelihood & $-604.96 * * *$ & $-658.17 * * *$ & 46.91 \\
& & & $-770.33 * * *$ \\
\hline
\end{tabular}

$* * * p \leq .01 ; * * p \leq .05 ; * p \leq .10$.

Additional findings. In line with the second and third contribution, we investigate marketing performance outcomes of the intervention. Thus, we conducted additional binary logistic regressions to examine the association between intervention participation and brand repurchase. For the CG1 EG1 sample, the change resulting from participation, versus not participating, was significant at the $1 \%$ level $(\beta=.65$, $\exp (\beta)=1.91)$. That is, participants were 1.9 times more likely to repurchase than nonparticipants. For the CG2 EG2 sample, the effects were in the same direction but more pronounced $(\beta=.70, \exp (\beta)=2.01, p<.01)$. Across the two intervention samples (EG EG2), participants in the disrupted condition were 1.5 times more likely to repurchase than those in the continuous condition $(\beta=.42, \exp (\beta)=$ $1.52, p<.05)$.

Brand satisfaction remained remarkably stable over time and all samples $(p>.10)$. Averaged over time, participants of either intervention reported higher brand satisfaction ratings than nonparticipants $(p<.05)$, despite small effect sizes. Brand satisfaction also had a positive effect on repurchase as can be seen in Table 3 (odd ratios 1.37 and 1.46 respectively). Product satisfaction was temporally variant $(p>.10)$, as customers' satisfaction declined over time, which is in line with previous literature (Nicolao, Irwin, and Goodman 2009). Yet, product satisfaction ratings did not differ across all samples $(p>.05)$. We included a covariate 
to control for whether participants engaged in self-reported dealer activities, such as regular test drives, during the survey period ( 1 = yes, $0=$ otherwise $)$ for the analyses regarding $\mathrm{H}_{1}-\mathrm{H}_{3}$. In the first two comparisons of treatment effects against a matched control group, this covariate was insignificant at $5 \%$.

Validation study. Experience disruption was associated with a longer experiential period (i.e., the full weekend as opposed to an afternoon), so its effect might be a result of duration, not the number of inserted breaks. To disentangle the two factors, we conducted an additional laboratory experiment.

We invited participants to play an interactive, enjoyable computer game and manipulated the duration (short, three minutes vs. long, five minutes) and the number of inserted breaks $(0,1$, or 2$)$, resulting in a $2 \times 3$ between-subject design, in which 289 students were randomly assigned to one of the six conditions. Participants in the no-break condition played continuously, whereas in the break conditions, they were told that they would experience one or two breaks, which equally partitioned the experience. During the break(s), the game stopped, and participants listened to a 30-second excerpt of a neutrally rated song $(\mathrm{M}=3.73$ on seven-point scale). After the game, participants rated the perceived emotional intensity of the experience. Specifically, we used positive affect measures based on selected adjectives (e.g., exciting, enjoyable) on a seven-point scale $(1=$ completely disagree, $7=$ completely agree). At the end, the items were merged into a composite measure $(\alpha=.86)$.

Regardless of the duration, respondents reported equal intensity ratings $\left(\mathrm{M}_{\text {short }}=5.26\right.$, $\left.\mathrm{M}_{\text {long }}=5.24 ; \mathrm{F}(1,282)=.02, p=.89\right)$. The main effect of the number of breaks was significant $(\mathrm{F}(2,282)=10.55, p<.01)$, but the interaction between duration and breaks was not $(p=.46)$. When respondents experienced one break, they reported significantly higher 
intensity than those who played continuously $\left(\mathrm{M}_{1 \text { break }}=5.25, \mathrm{M}_{\text {nobreak }}=4.84, p<.05\right)^{3}$, and those who had two breaks found the experience more intense than those with one $\left(\mathrm{M}_{2 \mathrm{breaks}}=\right.$ $\left.5.65, \mathrm{M}_{1 \text { break }}=5.25, p<.05\right)$. We also controlled for whether participants had played the game before, but the covariate was insignificant $(p=.36)$. Thus, simply extending hedonic experiences does not increase enjoyment, but inserting breaks intensifies hedonic experiences.

\footnotetext{
${ }^{3}$ Because we hypothesized a positive relationship between the number of breaks and enjoyment, we applied directional (one-tailed) significance levels for the pairwise comparisons.
} 


\section{Discussion}

\section{Theoretical Implications}

Consumers' emotional trajectories. While previous research shows that consumers' enjoyment with a product declines over time (Nicolao, Irwin, and Goodman 2009; Wang, Novemsky, and Dhar 2009), we posit that his downward trend even holds on a more abstract level, in that consumers' affect with the brand decays. The brand-related decline is weaker though and fades over time. We empirically substantiate the phenomenon of a temporal, emotional discharge between consumer and brand-a dark side process of long-term relationships. This finding substantially adds to research that has speculated about the existence of such brand-related emotional erosions (Batra, Ahuvia, and Bagozzi 2012).

In a business-to-consumer setting, such adaptation effects might benefit brands within consumers' evoked set by motivating consumers to seek new emotional stimulation. That means, an emotional discharge might encourage more consumption (Frank 1999), and if preference structures remain stable, emotional adaptation might feed a status quo bias, leading to consumer habituation in the repurchase decision. But an emotional discharge also entails negative consequences, because consumers lose their emotional connection to the current brand. They might turn to variety seeking to find new forms of stimulation in the offers of different firms (Ratner, Kahn, and Kahneman 1999).

Recharging customers emotionally. Complementary to existing a-priori strategies, we recommend a corrective, after-sales strategy to neutralize the consequences of time-variant brand affect. We empirically validate planned experience interventions as a mechanism to mitigate the gradual erosion of emotional brand connections. This emotional recharging tool supports the reinvigoration of consumer-brand relationships and helps mitigate the emotional 
decline in later relationship stages. Visceral, memorable experiences seem to serve as a natural antidote, because they help people reframe old information and remind consumers of positive brand information (Lyubomirsky et al. 2011). Schwarz and Xu (2011) also highlight how new attention to a brand is central to sustain appreciation of features that have been discounted by hedonic adaptation. This reasoning might also explain why participation in experience interventions, regardless of intensity, yields no negative consequences on product satisfaction; in fact, product satisfaction scores for the experimental groups were slightly higher than for the control groups, yet they were not significant. Drawing consumers' attention to new, exciting brand elements may come at a cost. Consider the example of the Jeep owner who participates in an off-road driving experience, using a newer model vehicle provided by the company. After this emotionally arousing activity, the owner may compare his or her current vehicle with the newer model and actually increase his or her reference points, such that the experience accelerates hedonic adaptation and devaluation of the current product (Kahneman and Tversky 1979). Yet, we do not uncover such cannibalization effects between product and brand-related outcome measures. In the absence of a potential cannibalization, we extend evidence about positive emotional activity effects to consumerbrand relationships (Lyubomirsky 2011; Mochon, Norton, and Ariely 2007).

Emotional injection continuum and performance outcomes. In more fine-grained inferences about the design of experience interventions, we find that disrupted interventions are more conducive to positive affect with the brand than are continuous interventions. Breaks might be important to allow the experiences to "sink in" with consumers, prompting their greater reflection and larger impact of actual activity (Seligman et al. 2005). Breaks also make consumers think about restarting the enjoyable experience (Loewenstein 1987).

While controlling for duration, we transfer the idea of consumption breaks from a laboratory setting to a real-life consumption context (Nelson and Meyvis 2008). The strong 
external validity of our findings offers a starting point for determining the appropriate intensity of experience interventions. With regard to marketing accountability, disrupted interventions invoke higher rates of customer retention.

Ethical perspectives on emotional recharging. Consumers often overestimate the affective impact of a purchase and buy material goods to which they rapidly adapt. In the context of hedonic adaptation, the ethical role of brands seems debatable: They encourage consumers to repeatedly walk the "hedonic treadmill" by acquiring new products (Raghunathan and Irwin 2001). Through this lens, recharge actions with new products also may be ethically questionable, because people rarely learn from their affective mistakes, so marketers could use experience interventions after every purchase, to promote repurchases of new car models and induce consumer overspending. After all, the creation and sale of new products drives firm value (Pauwels et al. 2004). Yet, we also find that participants report marginally higher product satisfaction immediately after an intervention, which suggests that interventions can defuse the adaptation effect in the short run. Consumers who reconnect with the brand gain increasing levels of enjoyment using the current product. In this sense, interventions do not have to be unethical but can benefit both the consumer and the brand.

\section{Managerial Implications}

Monitoring brand affect in long-term relationships. Firms should incorporate brand affect measures in their marketing dashboards and continuously track this metric over time. Our results substantiate the need to track if customers lose connection to the brand, endangering customer loyalty. A red flag in the customer relationship management system could act as an early warning to drastic drops in affect scores. By considering industryspecific repurchasing cycles, managers can effectively time their surveys and discrete interventions to thwart dangerous downward trends. The boost in brand affect might wane 
with time, as opposed to investments in brand satisfaction. Still, brand affect exerts an equally high impact on repurchase behavior. Hence, firms should invest complementarily in affectenhancing and satisfaction-facilitating activities. Affect-enhancing actions are rather discrete, with quantifiable associated costs.

Implementing recharge actions. Indirect experiences appear less engaging and trigger more cognitive responses (Millar and Millar 1996), which may be why passive marketing measures (e.g., advertising) cannot halt emotional erosion. Instead, we advise managers to produce direct experiences that are vivid, sensually enriching, and affectively charged. In line with the experience-journey concept, brand communications before and after the actual experience direct consumers' attention to planned experiences and let them reflect more intensively. For example, a test drive with a new model should come along with customer contacts by brand champion employees and tangible brand artifacts (e.g., souvenirs). Using new products as a central design element might promote novel brand experiences but harm experiences with the product - though our empirical findings do not support this latter aspect. Prior research reports that consumers often depreciate old products though. To tackle this potential double-edged sword, we suggest mixed participative treatments that combine new product- and brand-related elements.

Power of recharging. Our findings suggest greater effectiveness of disrupted versus continuous interventions. To achieve these interrupted consumption sequences, firms might include natural breaks, by extending the experience overnight, or provide clear incentives for customers to take breaks, such as by providing restaurant vouchers with a test drive. This suggestion resonates with a topical, long-standing debate in the automotive industry: whether to offer a test-drive for one or more days (Heiman 2010; Kim and Morris 2007). Firms also might train and incentivize frontline employees to recommend consumption breaks. In general 
though, reducing consumption monotony can help maximize the affective impact on participants.

Preventive relationship maintenance tools. In a broader sense, recharge actions represent investments in critical relationship stages to mitigate customer defection, comparable to "emotional booster sessions" in marital therapy to prevent relationship termination (Nelson et al. 2008). Preventive recovery actions constitute a sound, rewarding business strategy, because losing a customer is more expensive to the firm than implementing preventive interventions (Hogan, Lemon, and Libai 2003). Similar preventive techniques might be applicable in other durable goods contexts, such as high-technology electronic devices (e.g., notebooks, cell phones) with similar usage and purchasing cycles, whose value propositions tend to be based on hedonic product and brand benefits. In such settings, emotional recharge actions appear advisable and applicable: The high-tech firms could provide an ongoing flow of services around the products that provide multisensory hedonic stimuli, such as new sounds, pictures, or movies (e.g. iTunes for the iPod or the iPhone). They also might provide branded product add-ons to stimulate variation in physical appearance, such as new covers for cell phones or laptops. 


\section{Limitations and Avenues for Further Research}

Our work is not without limitations, some of which suggest opportunities for further research. In particular, the results are subject to typical internal validity concerns associated with field experiments, though the data collection entails several years and resources beyond those available to most academic research. We traded off a lab environment for a unique opportunity to increase the realism and external validity of our study, in line with the suggestion that scholars should spend more time with managers to enhance academics' contributions to marketing practice (Jaworski 2011).

In this first study to detect the erosion of consumer-brand relationships in the context of hedonic adaptation, we test the phenomenon with an exciting car brand. Affective erosion might not influence less exciting brands in the same way. The operationalization of the experience interventions also builds on novel product experiences and interruptions as central design factors. However, there are multiple ways to design interventions that vary the level of associated emotion. For example, researchers might break the gestalt of the experience into several specific dimensions (e.g., sensory, intellectual) and explore whether some dimensions are more powerful than others for transmitting recharging effects (Brakus, Schmitt, and Zarantonello 2009). The efficacy and strength of the emotional recharge also might depend on individual factors, such as consumers' attachment to material belongings or their general tendency to engage with brands (Nicolao, Irwin, and Goodman 2009; Sprott, Czellar, and Spangenberg 2009).

Overall then, additional studies should validate and replicate our findings in durable goods contexts other than the automotive industry and investigate which conditions make recharging effects more pronounced. Such activities ultimately seem valuable for firms, yet customer compliance was moderate in our sample. Researchers should determine how firms 
can target and motivate potential participants most effectively to increase compliance rates. As a starting point, the covariates used in the propensity score matching procedure could offer insights into the characteristics of typical compliers. 


\section{Conclusion}

Extant research describes ways to defuse adaptation before a discrete product choice by improving affective forecasting (Nelson and Meyvis 2008; Wang, Novemsky, and Dhar 2009). We instead consider the exploration and management of adaptation dynamics toward brands by studying a real purchase and repurchase decision context. Direct experience interventions are becoming increasingly popular in the marketplace, and we find that in an after-sales context, they offer a new and promising tool to ward off consumers' fading brand affect. 
Chapter 4

Conclusion 


\section{Synopsis}

Over the last 25 years, the proficient management of long-term relationships has received enormous attention in the marketing literature (Gummesson 1987). Since then, practitioners and academics alike have embraced the concept of relationship marketing and produced large evidence for adopting a relational business perspective (Morgan and Hunt 1994; Payne and Frow 2005). In an effort to understand and serve customers better, most recent reports show that worldwide investments in CRM technology grew by $12.5 \%$ to 18 billion US dollars in 2012 (Gartner 2013). Including all CRM-related services, such as consulting for example, global expenditures are said to exceed the 100 billion US dollar threshold (Zablah, Bellenger, and Johnston 2004). Such numbers highlight the agreement about the general benefits derived from the implementation of relationship management practices (Hibbard et al. 2001; Ryals 2005), although the effectiveness of relationship marketing efforts varies contextually (Palmatier et al. 2006). The benefits are most pronounced in the stage of relationship maintenance (Reinartz, Krafft, and Hoyer 2004), which underlines the relevance of this dissertation to explore this particular stage in the B2C and $\mathrm{B} 2 \mathrm{~B}$ domains.

In the B2C domain, affective ties between customers and brands play a pivotal role in driving and maintaining business success (Batra, Ahuvia, and Bagozzi 2012; Verhoef 2003; Yim, Tse, and Chan 2008). Nevertheless, the strength and change in customers' affective reactions towards a brand have received little attention in the relationship maintenance literature. Yet, the temporal fading of customers' emotional connection with a brand might contribute to explaining profitability problems of long-term customers, which has been reported earlier (Reinartz and Kumar 2002). Likewise, a small literature stream in the B2B area notes that close relationships between buyers and sellers suffer from declining 
profitability over time (Anderson and Jap 2005; Hibbard et al. 2001). Concurrently, the reasons for the emergence of these dark side processes remain largely obscure. Correspondingly, the overall goal of this dissertation is to deepen our understanding about the dynamics of long-term relationships, and suggest appropriate tools to sustain relationship performance.

In study one, we selected a buyer-supplier context and recruited purchasing professionals. Buyer-supplier relationships are a generic form of long-term B2B relationships, allowing us to study dark side effects and suitable strategies to sustain close relationships.

First, we reveal in line with social exchange theory and the customer entitlement literature some of the psychological processes which activate subtle corrosive forces in longterm relationships, known as the dark side. In this vein, we contribute to the emerging dark side literature by conceptualizing buyer complacency as a central symptom that arises when buyers are too comfortable with their supplier and stop monitoring relational performance as a result of excessive trust.

Second, we find that buyer complacency nourishes other negative dark side symptoms: buyer suspicion (i.e., developing doubts about the supplier's truthfulness), vulnerability (i.e., feeling exposed to potentially harmful actions), and myopia (i.e., being too shortsighted in defining the business perspective). Feelings of suspicion and vulnerability increase the attractiveness of supplier alternatives, while a myopic tunnel vision reduces buyers' perceptions about the attractiveness of supplier alternatives. Thus, we explore concrete symptoms underlying previously reported performance dips (Anderson and Jap 2005; Hibbard et al. 2001; Scheer 2012), and describe their interconnectedness.

Third, we are the first to offer empirical insights on how to fight the dark side in longterm exchange relationships. Specifically, we find that developing concrete common goals, 
and a periodic screening of alternative partners, helps buyers monitor and identify dark side developments. On the contrary, listing dedicated assets in the belief to show relationship commitment might cement the status quo, thus amplifying complacency, which is a deceptive relationship destabilizer in the long-run.

Study two then turns to examining potential dark side processes and suitable suppressor mechanisms in a B2C setting. Hence, we recruited private customers in the automotive industry to study their affective trajectories and purchasing behavior in long-term relationships. Additionally, a lab experiment among business students was conducted.

First, we inspect the temporal role of brand affect in our field study and find a decline in the passage of time. Our results confirm conjectures in line with hedonic adaptation theory that brands lose their power to emotionally arouse customers due to heightened expectations and habituation. As a result, positive brand experiences become more mediocre in the course of usage and ownership. As consumer-brand relationships require constant monitoring (Yim, Tse, and Chan 2008), this finding implies that managers experience drastic negative consequences for customer loyalty and potentially customer profitability, if they dare put emotional customer-brand relationships on cruise-control. In line with study one, this partial erosion of affect could be classified as a dark side symptom in the $\mathrm{B} 2 \mathrm{C}$ context and has significant managerial implications, given the external validity of the finding.

Second, we build on this novel finding of an affective decline to propose a suitable intervention mechanism. Most studies focus on defusing hedonic adaptation in a nonrelational, pre-purchase context (Nicolao, Irwin, and Goodman 2009; Wang, Novemsky, and Dhar 2009). We enrich current research by offering planned experience interventions as a mechanism to thwart hedonic adaptation in a relationship management context. Planned experience interventions engage customers in multisensory activities that trigger consumers' 
senses and attention, thereby nurturing brand affect. Such findings are particularly relevant for manufacturers of durable goods, as these must deliver customer value over greater time horizons. We find that experience interventions serve as a vehicle to boost customer loyalty in close long-term relationships.

Third, we add to the current literature by investigating potential nuances in the effectiveness of the adaptation-defusing mechanism. We show that disrupted interventions are more powerful than continuous interventions in boosting customer brand affect, and loyalty, hence increasing profitability. These findings externally validate previous theoretical considerations about inserting breaks in consumption experiences (Nelson and Meyvis 2008), and give managers concrete recommendations on the design of experience interventions. In fact, the employment of a lab and a field experiment substantiate the external and internal validity of our findings. 


\section{Further Research Suggestions}

For both studies, specific avenues for further research have been discussed. Nevertheless, we would like to discuss some general directions for future research in the domain of long-term relationship management.

In chapter two, we conceptualize the dark side and test the effectiveness of the proposed suppressor strategies via a cross-sectional survey. Implicitly, the assumption is that these strategies are effective in the long-run because buyers use them in an ongoing, wellfunctioning business relationship. Otherwise, the relationships at hand might have been dissolved in earlier stages already. Still, it would be interesting to explicitly test whether the effects play out in a similar direction and magnitude in the long-run. For instance, would the effects of goal specificity also hold when buyers and suppliers become familiar and habitual towards establishing specific common goals? This issue might be less obvious but also potentially important for the findings of chapter three. In an attempt to spot dark side processes in a $\mathrm{B} 2 \mathrm{C}$ context, we examine the longitudinal effects of an intervention on firsttime customers' brand affect. What happens, if consumers receive repeated exposure to experience interventions? Would the effects of a continuous or disrupted experience intervention tapper off, if customers participate a second or third time in such an event? Hedonic adaptation theory might suggest that repeated exposure to an intervention will discount its effectiveness in the long-run. Additionally, markets are competitive and once proven effective, it is likely that consumers are enticed by multiple firms to participate in various interventions (Heiman 2010). Hence, this raises the question to what extent firms can sustain the effect of the intervention mechanism in the long-run. In this regard, it might be valuable to experiment with other modifications in intervention design, beyond continuation and disruption, to increase effectiveness in the long-run. 
Other than that, this dissertation offers a first list of viable strategies to suppress the dark side, which is by far not complete. In chapter two, we derive the most promising strategies based on the state-of-the-art knowledge of the B2B literature. Still, we encourage researchers to replicate our results and extend the discussion by deriving new potential variables or concepts to keep the dark side at bay. The conceptualization of the dark side from a buyer's perspective might be helpful in this respect.

The general efficacy of the strategies might also depend on other factors which strengthen or attenuate the proposed relationships. For example, testing personal characteristics could enrich the discussion on how to circumvent negative effects, such as complacency. Some persons might be innately more ambitious and disciplined, and hence more likely to combat the growth of self-satisfaction. In this sense, they remain more objective about the status quo, and they stay vigilant despite recent achievements or successes. If we extrapolate this thought from an individual to a firm level, organizational factors might also act as moderating influences. Some firms show higher competitive responsiveness in positive times (Chen 1996), so it might be valuable to use this as a potential avenue to explore other complacency defusing mechanisms.

It is important to note that the derivation of the dark side symptoms and the suppressor strategies see the buyer, or the customer, as the focal reference point. The major reason for this is the underlying assumption that customers have greater power and motivation in shaping the course of a business relationship. However, the level of the relational dark side symptoms and the efficacy of the strategies depend on the supplier, too. Extending the unidirectionality of the dark-side conceptualization could be interesting to explore a more accurate picture of an interactive, dyadic relationship. Intuitively, dark side symptoms such as buyer complacency might spill over and amplify supplier complacency. For instance, customers who increasingly take soft-bargaining positions might encourage suppliers to take 
business for granted, thus becoming less willing to go the extra mile (Brennan 1997). Similarly, buyer complacency could trigger supplier myopia if the supplier focuses on exploiting an "easy-to-serve" customer while neglecting to innovate business practices to stay competitive. Hence, adopting a dyadic perspective on the dark side research, and exploring spill-over effects between the two parties might be a valuable avenue for further research.

Various factors have been explored which undermine the bottom-line effects of relationship marketing actions, yet the dark side notion has not been associated with longterm relationships in the $\mathrm{B} 2 \mathrm{C}$ setting. Brand affect and its erosion over time is one corrosive mechanism that is detrimental to customer loyalty and profits. Not necessarily coupled to hedonic adaptation but even more broadly, it is worth exploring instruments other than experience interventions, which are under management control and serve to increase customer retention. Likewise, up to $47 \%$ of all CRM campaigns fail due to poor implementation, so it might be interesting to explore critical success factors for implementation in this regard (Band 2008). 


\section{Managerial Implications}

Companies spend billions of dollars on maintaining strong relationships, as they are integral to achieving competitive advantage. While the stage of relationship maintenance is most promising to improve bottom-line results (Reinartz, Krafft, and Hoyer 2004), maintaining strong relationships over greater time horizons is far from easy. We would like to make two major concluding remarks on how to sustain performance in long-term relationships.

First, long-term relationships between buyers and sellers are essential in a B2B environment to lower costs, increase efficiency, and improve corporate performance. However, from the very positive building blocks (i.e., satisfaction and trust) of these closeknit relationships, negative sentiments germinate over time, decreasing relational productivity. Specifically, ongoing relationships suffer from relational coziness and high trust as partners often adopt a take-it-for-granted mentality, and subsequently lack the esprit and effort to innovate the relationship in tune with market dynamics. At the same time, switching costs are high and partners are dependent on each other. To sustain relationship performance, our findings show that companies could implement mechanisms that encourage buyersupplier goal-setting and periodic performance benchmarking. Simultaneously, it is unwise to dedicate substantial relationship assets in an effort to make a "fresh start" after the onset of the dark side.

Second, while consumers seek value in early stages of B2C relationships, emotional ties towards a brand become more important drivers of customer retention in mature relationships (Johnson, Herrmann, and Huber 2006). In fact, emotional connectivity often elevates a brand beyond price and competition, thus decommoditizing a business (Berry and Carbone 2007). Yet, our findings indicate that customers' emotional ties with brands wane 
over time, endangering relationship continuity and company profits. Thus, managers are advised to track and analyze customers' emotional trajectories over the relationship lifecycle. Beyond monitoring, we recommend that managers design and implement discrete experience actions as a proactive relationship maintenance tool to drive customers' emotions in critical relationship periods. Experience actions engage customers, appeal to their senses, and foster the co-creation of emotional activity effects (Zomerdijk and Voss 2010). That way, companies can sustain emotional connections by creating compelling experiences which inject new relationship salience and meaning. 


\section{Final Thought}

The maintenance of long-term relationships is a challenging and very fundamental issue that applies to almost all peoples' private and professional life. In the professional arena, forging close relationships has practically become a strategic mantra to enhance business performance. Despite all the noted positive benefits, and somewhat against current belief, this dissertation outlines the potential pitfalls and challenges which are associated with growing closer in long-term relationships. Its central premise is that time changes how relationship partners evaluate each other, unfortunately not for the better in most instances. Starting from this premise, the dissertation is an attempt to shed light on negative effects in long-term relationships and recommend appropriate measures to re-invigorate relationship productivity. Hopefully, this knowledge helps to dissipate dark clouds which appear on the horizon in some relationships. Against the central premise of the dissertation, The Rolling Stones would be right then in saying: time is on our side. 


\section{References}

Aggarwal, Pankaj (2004), "The Effects of Brand Relationship Norms on Consumer Attitudes and Behavior," Journal of Consumer Research, 31 (1), 87-101.

Anand, Jaideep and Harbir Singh (1997), "Asset redeployment, acquisitions and corporate strategy in declining industries," Strategic Management Journal, 18 (S1), 99-118.

Anderson, Erin and Sandy Jap (2005), "The dark side of close relationships," MIT Sloan Management Review, 46 (3), 75-82.

Anderson, James and James Narus (1984), "A model of the distributor's perspective of distributor-manufacturer working relationships," The Journal of Marketing, 48 (4), 62-74.

(1991), "Partnering as a Focused Market Strategy," California Management Review, 33 (Spring), 95-113.

Argyris, Chris (1968), "Some unintended consequences of rigorous research," Psychological Bulletin, 70 (3), 185-197.

Auto Editors of Consumer Guide (2011), "Jeepers Jamboree," (accessed March 7, 2011), [available at http://auto.howstuffworks.com/jeepers-jamboree5.htm].

Baker, Brent (2009), An Empirical Examination of the Dark Side of Relationship Marketing within a Business to Business Context. Department of Marketing. Tampa, University of South Florida. PhD.

Baker, Rosie (2011), “Car makers must appeal to emotions,” Marketing Week, 34 (37), 4.

Band, William (2008), "Answers To Five Frequently Asked Questions About CRM Projects," (accessed May 6, 2013), [available at http://www.forrester.com/Answers+To+Five+Frequently+Asked+Questions+About+CRM+P rojects/fulltext/-/E-RES46432].

Barney, Jay and Mark Hansen (1994), "Trustworthiness as a Source of Competitive Advantage," Strategic Management Journal, 15 (S1), 175-190.

Batra, Rajeev, Aaron Ahuvia and Richard Bagozzi (2012), "Brand Love," Journal of Marketing, 76 (2), 1-16. 
Beamish, Paul (1985), "The characteristics of joint ventures in developed and developing countries," Transnational Corporations and Business Strategy, 20 (3), 338-351.

Bentenrieder, Matthias, Peter Cochrane, Hilmar Dunker, Franz-Rudolf Esch, Tom Gasser, Rolf Isermann, Andreas Knie, Horst Leonberger, Markus Lienkamp, Helmut Matschi, KarlFriedrich Stracke and Thilo Weichert (2011), Automotive Agenda 12. Wiesbaden: Springer Automotive Media.

Bergquist, Scott (2006), "The perfect market-and strategies to survive it," Journal of Business Strategy, 27 (2), 11-20.

Berry, Leonard (1995), "Relationship marketing of services-growing interest, emerging perspectives," Journal of the Academy of Marketing Science, 23 (4), 236-245.

Berry, Leonard and Lewis Carbone (2007), "Build Loyalty Through Experience Management," Quality Progress, 40 (9), 26-32.

Beverland, Michael, Francis Farrelly and Zeb Woodhatch (2004), "The role of value change management in relationship dissolution: Hygiene and motivational factors," Journal of Marketing Management, 20 (9-10), 927-939.

Boughton, Paul, Linda Nowak and Judith Washburn (1996), "A decision model for marketing research relationship choices," Journal of Services Marketing, 10 (1), 56-69.

Boyd, Henry and Janet Helms (2005), "Consumer Entitlement Theory and Measurement," Psychology \& Marketing, 22 (3), 271-286.

Brakus, Josko, Bernd Schmitt and Lia Zarantonello (2009), "Brand Experience: What Is It? How Is It Measured? Does It Affect Loyalty?,” Journal of Marketing, 73 (3), 52-68.

Brennan, Ross (1997), "Buyer/supplier partnering in British industry: the automotive and telecommunications sectors," Journal of Marketing Management, 13 (8), 759-775.

Brickman, Philip, Dan Coates and Ronnie Janoff-Bulman (1978), "Lottery winners and accident victims: Is happiness relative?," Journal of Personality and Social Psychology, 36 (8), 917-927.

Burt, David, Donald Dobler and Stephan Starling (2003), World class Supply Management. Irwin, NY: McGraw-Hill 
Butori, Raphaëlle (2010), "Proposition for an Improved Version of the Consumer Entitlement Inventory," Psychology \& Marketing, 27 (3), 285-298.

Caliendo, Marco and Sabine Kopeinig (2008), "Some Practical Guidance For The Implementation Of Propensity Score Matching," Journal of Economic Surveys, 22 (1), 31-72.

Cannon, Joseph and William Perreault (1999), "Buyer-seller relationships in business markets," Journal of Marketing Research, 36 (4), 439-460.

Carver, Charles and Michael Scheier (1982), "Control-Theory: A Useful Conceptual Framework for Personality-Social, Clinical, and Health Psychology," Pyschological Bulletin, $92(1), 111-135$.

Challagalla, Goutam, R. Venkatesh and Ajay Kohli (2009), "Proactive Postsales Service: When and Why Does It Pay Off?," Journal of Marketing, 73 (2), 70-87.

Chaudhuri, Arjun and Morris Holbrook (2001), "The chain of effects from brand trust and brand affect to brand performance: the role of brand loyalty," Journal of Marketing, 65 (2), 81-93.

Chen, Injazz and Antony Paulraj (2004), "Towards a theory of supply chain management: the constructs and measurements," Journal of Operations Management, 22 (2004), 119-150.

Chen, Ming-Jer (1996), "Competitor Analysis and Interfirm Rivalry: Toward a Theoretical Integration," Academy of Management Review, 21 (1), 100-134.

Chin, Wynne (1998), "The Partial Least Squares Approach to Structural Equation Modeling," in Modern Methods for Business Research, George A Marcoulides, ed. NJ: Lawrence Erlbaum Associates.

Christopher, Martin and Uta Jüttner (2000), "Developing strategic partnerships in the supply chain: a practitioner perspective," European Journal of Purchasing \& Supply Management, 6 (2), 117-127.

Clark, Maxine (2013), "The Beary Beginning," (accessed January 16, 2013), [available at http://www.buildabear.co.uk/aboutus/ourcompany/ourstory.aspx].

Claycomb, Cindy and Gary Frankwick (2004), "A Contingency Perspective of Communication, Conflict Resolution and Buyer Search Effort in Buyer-Supplier Relationships," Journal of Supply Chain Management, 40 (1), 18-34. 
Craig, Samuel and James Ginter (1975), "An Empirical Test of a Scale for Innovativeness," in Advances of Consumer Research, Mary Jane Schlinger, ed. Ann Arbor, MI: The Association for Consumer Research, 2: 555-562.

Cropanzano, Russell and Marie Mitchell (2005), "Social exchange theory: An interdisciplinary review," Journal of Management, 31 (6), 874-900.

Crothers, Brooke (2011), "Despite legal battle, Apple keeps Samsung inside iPhone," (accessed January 15, 2013, [available at http://news.cnet.com/8301-13924_3-2010847964/despite-legal-battle-apple-keeps-samsung-inside-iphone/].

Dant, Rajiv and Aaron Gleiberman (2011), "Preventing and combating the onset of dark-side symptoms," Journal of Marketing Management, 27 (13-14), 1426-1443.

Deshpande, Rohit and Hubert Gatingon (1994), "Competitive analysis," Marketing Letters, 5 (3), 271-287.

Deutsch, Morton (1958), "Trust and Suspicion," The Journal of Conflict Resolution, 2 (4), 265-279.

Dunn, Elizabeth, Daniel Gilbert and Timothy Wilson (2011), "If money doesn't make you happy then you probably aren't spending it right," Journal of Consumer Psychology, 21 (2), 115-125.

Dyer, Jeffrey, Prashant Kale and Harbit Singh (2004), "When to ally and when to acquire," Harvard Business Review, 82 (7-8), 109-115.

Elmuti, Dean and Yunus Kathawala (2001), "An overview of strategic alliances," Management Decision, 39 (3), 205-218.

Emerson, Richard (1976), "Social exchange theory," Annual Review of Sociology, 2 (1), 335362.

Endsley, Mica and Daniel Garland (2000), Situation awareness: analysis and measurement. Marwah, NJ: Lawrence Erlbaum Associates.

Ephross, Paul and Thomas Vassil (1993), “The rediscovery of real-world groups," Social Work With Groups, 16 (1-2), 15-25.

Erdem, Tülin, Joffre Swait and Ana Valenzuela (2005), "Brands as Signals: A Cross-Country Validation Study," Journal of Marketing, 70 (1), 34-49. 
Fang, Eric, Robert Palmatier and Kenneth Evans (2004), "Goal-setting paradoxes? Trade-offs between working hard and working smart: The United States versus China," Journal of the Academy of Marketing Science, 32 (2), 188-202.

Fischer, Marc, Franziska Völckner and Henrik Sattler (2010), "How important are brands? A cross-category, cross-country study," Journal of Marketing Research, 47 (5), 823-839.

Flint, Daniel, Robert Woodruff and Sarah Gardial (1997), "Customer value change in industrial marketing relationships: A call for new strategies and research," Industrial Marketing Management, 26 (2), 163-175.

Fordyce, Michael (1983), "A program to increase happiness: Further studies," Journal of Counseling Psychology, 30 (4), 483-498.

Fornell, Claes and David Larcker (1981), "Evaluating structural equation models with unobservable variables and measurement error," Journal of Marketing Research, 18 (1), 3950 .

Fournier, Susan (1998), "Consumers and Their Brands: Developing Relationship Theory in Consumer Research," Journal of Consumer Research, 24 (March), 343-373.

Frank, Robert (1999), Luxury fever: Why money fails to satisfy in an era of excess. New York: Free Press.

Frederick, Shane and George Loewenstein (1999), "Hedonic Adaptation," in Well-Being: The Foundations of Hedonic Psychology, Daniel Kahneman, Ed Diener, and Norbert Schwarz, ed. New York: Russell Sage Foundation: 302-329.

Fullerton, Gordon (2005), "The Impact of Brand Commitment on Loyalty to Retail Service Brands," Canadian Journal of Administrative Sciences / Revue Canadienne des Sciences de l'Administration, 22 (2), 97-110.

Ganesan, Shankar (1994), "Determinants of Long-Term Orientation in Buyer-Seller Relationships," Journal of Marketing, 58 (2), 1-19.

Gartner (2013), "Gartner Says Worldwide Customer Relationship Management Software Market Grew 12.5 Percent in 2012," (accessed May 6, 2013), [available at http://www.gartner.com/newsroom/id/2459015].

Ghoshal, Sumantra and Peter Moran (1996), "Bad for Practice: A Critique of the Transaction Cost Theory," The Academy of Management Review, 21 (1), 13-47. 
Gilbert, Daniel, Elizabeth Pinel, Timothy Wilson, Stephen Blumberg and Talia Wheatley (1998), "Immune neglect: A source of durability bias in affective forecasting," Journal of Personality and Social Psychology, 75 (3), 617-638.

Gronhaug, Kjell, Inge Jan Henjesand and Anita Koveland (1999), "Fading Relationships in Business Markets: An Exploratory Study,” Journal of Strategic Marketing, 7 (3), 175-190.

Gummesson, Evert (1987), "The new marketing-Developing long-term interactive relationships," Long Range Planning, 20 (4), 10-20.

Hair, Joseph, Christian Ringle and Marko Sarstedt (2011), "PLS-SEM: Indeed a silver bullet," The Journal of Marketing Theory and Practice, 19 (2), 139-152.

Hanvanich, Sangphet, K. Sivakumar and Tomas Hult (2006), "The relationship of learning and memory with organizational performance: the moderating role of turbulence," Journal of the Academy of Marketing Science, 34 (4), 600-612.

Harkins, Stephen and Jeffrey Jackson (1985), "The Role of Evaluation in Eliminating Social Loafing," Journal of Personality and Social Psychology, 11 (4), 457-465.

He, Yi and Qimei Chen (2011). The effect of fit on hedonic adaptation.American Marketing Association Winter Camp. Austin, TX. 7-8.

Heide, Jan and George John (1988), "The Role of Dependence Balancing in Safeguarding Transaction-Specific Assets in Conventional Channels," Journal of Marketing, 52 (1), 20-35.

Heiman, Amir (2010), "The economics of demonstrations: The effect of competition on demonstration and pricing strategies," Marketing Letters, 21 (4), 351-363.

Helsen, Kristiaan and David Schmittlein (1993), "Analyzing Duration Times in Marketing: Evidence for the Effectiveness of Hazard Rate Models," Marketing Science, 11 (4), 395-414.

Helson, Harry (1964), Adaptation-level theory. New York: Harper \& Row.

Hibbard, Jonathan, Frédéric Brunel, Rajiv Dant and Dawn Iacobucci (2001), "Does Relationship Marketing Age Well?," Business Strategy Review, 12 (4), 29-35.

Hibbard, Jonathan, Nirmalya Kumar and Louis Stern (2001), "Examining the impact of destructive acts in marketing channel relationships," Journal of Marketing Research, 38 (1), 45-61. 
Hogan, John, Katherine Lemon and Barak Libai (2003), "What is the true value of a lost customer?," Journal of Service Research, 5 (3), 196-208.

Holmqvist, Mikael (2004), "Experiential learning processes of exploitation and exploration within and between organizations: An empirical study of product development," Organization Science, 15 (1), 70-81.

Hulland, John (1999), "Use of partial least squares (PLS) in strategic management research: A review of four recent studies," Strategic Management Journal, 20 (2), 195-204.

Hult, Tomas and Ernest Nichols (1999), "A study of team orientation in global purchasing," Journal of Business \& Industrial Marketing, 14 (3), 194-212.

Imbens, Guido and Jeffrey Wooldridge (2009), "Recent Developments in the Econometrics of Program Evaluation," Journal of Economic Literature, 47 (1), 5-86.

Inkpen, Andrew and Paul Beamish (1997), "Knowledge, Bargaining Power, and the Instability of International Joint Ventures," The Academy of Management Review, 22 (1), 177 202.

Jackson, Barbara (1985), "Build customer relationships that last," Harvard Business Review, 63 (6), 120-128.

Jap, Sandy (1999), "Pie-expansion efforts: collaboration processes in buyer-supplier relationships," Journal of Marketing Research, 36 (4), 461-475.

Jap, Sandy and Erin Anderson (2003), "Safeguarding interorganizational performance and continuity under ex post opportunism," Management Science, 49 (12), 1684-1701.

Jaworski, Bernard (2011), “On Managerial Relevance,” Journal of Marketing, 75 (4), 211 224.

Jayachandran, Satish and Rajan Varadarajan (2006), "Does success diminish competitive responsiveness? Reconciling conflicting perspectives," Journal of the Academy of Marketing Science, 34 (3), 284-294.

Johannessen, Jon-Arild, Bjørn Olsen and Thomas Lumpkin (2001), "Innovation as newness: what is new, how new, and new to whom?," European Journal of Innovation Management, 4 (1), 20-31. 
Johnson, Michael, Andreas Herrmann and Frank Huber (2006), "The evolution of loyalty intentions," Journal of Marketing, 70 (2), 122-132.

Jordan, Silvia, Martin Messner and Albrecht Becker (2009), "Reflection and mindfulness in organizations: Rationales and possibilities for integration," Management Learning, 40 (4), 465-473.

Kahneman, Daniel and Jackie Snell (1990), "Predicting Utility," in Insights in Decision Making: A Tribute to Hillel J. Einhorn, Robin Hogarth, ed. Chicago: University of Chicago Press: 295-310.

Kahneman, Daniel and Amos Tversky (1979), "Prospect theory: An analysis of decision under risk," Econometrica: Journal of the Econometric Society, 47 (2), 263-291.

Kale, Prashant and Harbir Singh (2009), "Managing strategic alliances: what do we know now, and where do we go from here?," The Academy of Management Perspectives, 23 (3), 4562 .

Karau, Steven and Kipling Williams (1993), "Social loafing: A meta-analytic review and theoretical integration,” Journal of Personality and Social Psychology, 65 (4), 681.

Kee, Herbert and Robert Knox (1970), "Conceptual and Methodological Considerations in the Study of Trust and Suspicion," The Journal of Conflict Resolution, 14 (3), 357-366.

Keller, Kevin and Donald Lehmann (2006), "Brands and Branding: Research Findings and Future Priorities," Marketing Science, 25 (6), 740-759.

Kempf, DeAnna (1999), “Attitude formation from product trial: Distinct roles of cognition and affect for hedonic and functional products," Psychology and Marketing, 16 (1), 35-50.

Kim, Jooyoung and Jon Morris (2007), "The power of affective response and cognitive structure in product-trial attitude formation," Journal of Advertising, 36 (1), 95-106.

Kumar, Nirmalya, Lisa Scheer and Jan-Benedict Steenkamp (1995), "The effects of perceived interdependence on dealer attitudes," Journal of Marketing Research, 32 (3), 348356.

Laughlin, Ron (2007), Conquering Complacency in Sales: Are You Whining Your Way Out of Business? Angel Fire, NM: Complacency Curve Publishing. 
Lechner, Michael (2002), "Program heterogeneity and propensity score matching: An application to the evaluation of active labor market policies," Review of Economics and Statistics, 84 (2), 205-220.

Leuven, Edwin and Barbara Sianesi (2003). PSMATCH2: Stata module to perform full Mahalanobis and propensity score matching, common support graphing, and covariate imbalance testing.

Levine, Timothy and Steven McCornack (1991), "The dark side of trust: Conceptualizing and measuring types of communicative suspicion," Communication Quarterly, 39 (4), 325-340.

Levitt, Theodore (1960), “Marketing Myopia,” Harvard Business Review, 38 (4), 45-56.

Loewenstein, George (1987), "Anticipation and the valuation of delayed consumption," The Economic Journal, 97 (387), 666-684.

Lovemarks (2013), "Products That Are Easy to Love," (accessed 2013, January 16), [available at http://www.lovemarks.com/index.php?pageID=20015\&lovemarkid=135].

Lucas, Richard and Andrew Clark (2006), "Do people really adapt to marriage?," Journal of Happiness Studies, 7 (4), 405-426.

Lund, Mary (1985), "The development of investment and commitment scales for predicting continuity of personal relationships," Journal of Social and Personal Relationships, 2 (1), 3 23.

Luo, Xueming (2002), "Trust production and privacy concerns on the Internet: A framework based on relationship marketing and social exchange theory," Industrial Marketing Management, 31 (2), 111-118.

Lyubomirsky, Sonja (2011), "Hedonic adaptation to positive and negative experiences," in Oxford handbook of stress, health, and coping, Susan Folkman, ed. New York: Oxford University Press: 200-224.

Lyubomirsky, Sonja, Rene Dickerhoof, Julia Boehm and Kennon Sheldon (2011), "Becoming happier takes both a will and a proper way: An experimental longitudinal intervention to boost well-being," Emotion, 11 (2), 391.

Lyubomirsky, Sonja, Kennon Sheldon and David Schkade (2005), "Pursuing Happiness: The Architecture of Sustainable Change," Review of General Psychology, 9 (2), 111-131. 
March, James (1991), "Exploration and exploitation in organizational learning," Organization Science, 2 (1), 71-87.

Matsuno, Ken, John Mentzer and Joseph Rentz (2000), "A refinement and validation of the MARKOR scale," Journal of the Academy of Marketing Science, 28 (4), 527-539.

Maxham, James and Richard Netemeyer (2002), "A Longitudinal Study of Complainig Customers' Evaluations of Multiple Service Failures and Recovery Efforts," Journal of Marketing, 66 (October), 57-71.

McAlexander, James, John Schouten and Harold Koenig (2002), "Building Brand Community," Journal of Marketing, 66 (1), 38-54.

Mealli, Fabrizia and Donald Rubin (2003), "Assumptions allowing the estimation of direct causal effects," Journal of Econometrics, 112 (1), 79-87.

Merriam-Webster Dictionary (2013), (accessed February 26, 2013), [available at http://www.merriam-webster.com/dictionary/complacency].

Millar, Murray and Karen Millar (1996), "The effects of direct and indirect experience on affective and cognitive responses and the attitude-behavior relation," Journal of Experimental Social Psychology, 32 (6), 561-579.

Mochon, Daniel, Michael Norton and Dan Ariely (2007), "Getting Off the Hedonic Treadmill One Step at a Time: The Impact of Regular Religious Practice and Exercise on Well-Being," Journal of Economic Psychology, 29 (5), 632-642.

Moorman, Christine, Gerald Zaltman and Rohit Deshpande (1992), "Relationships between providers and users of market research: the dynamics of trust within and between organizations," Journal of Marketing Research, 29 (3), 314-328.

Moray, Neville and Toshiyuki Inagaki (2000), “Attention and complacency," Theoretical Issues in Ergonomics Science, 1 (4), 354-365.

Morgan, Robert and Shelby Hunt (1994), “The commitment-trust theory of relationship marketing," The Journal of Marketing, 58 (3), 20-38.

Nelson, Judith, Chi-Sing Li, Daniel Eckstein, Pedra Ane and William Mullener (2008), "Antidotes for Infidelity and Prescriptions for Long Lasting Relationships: Four Couples' Activities," The Family Journal, 16 (4), 375-378. 
Nelson, Leif and Tom Meyvis (2008), "Interrupted consumption: disrupting adaptation to hedonic experiences," Journal of Marketing Research, 45 (6), 654-664.

Nicolao, Leonardo, Julie Irwin and Joseph Goodman (2009), "Happiness for Sale: Do Experiential Purchases Make Consumers Happier than Material Purchases?," Journal of Consumer Research, 36 (2), 188-198.

Nielson, Charles (1996), “An empirical examination of switching cost investments in business-to-business marketing relationships," Journal of Business \& Industrial Marketing, 11 (6), 38-60.

Palmatier, Robert, Rajiv Dant, Dhruv Grewal and Ken Evans (2006), "Factors influencing the effectiveness of relationship marketing: a meta-analysis," Journal of Marketing, 70 (4), 136153.

Parasuraman, Raja, Robert Molloy and Indramani Singh (1993), "Performance consequences of automation-induced 'complacency'," The International Journal of Aviation Psychology, 3 (1), 1-23.

Park, Choong, Deborah MacInnis, Joseph Priester, Andreas Eisingerich and Dawn Iacobucci (2010), "Brand Attachment and Brand Attitude Strength: Conceptual and Empirical Differentiation of Two Critical Brand Equity Drivers," Journal of Marketing, 74 (6), 1-17.

Parsons, Amy (2002), "What Determines Buyer-Seller Relationship Quality? An Investigation from the Buyer's Perspective,” Journal of Supply Chain Management, 38 (2), 4-12.

Patrick, Vanessa, Deborah MacInnis and Choong Park (2007), "Not as Happy as I Thought I'd Be? Affective Misforecasting and Product Evaluations," Journal of Consumer Research, 33 (4), 479-489.

Pauwels, Koen, Jorge Silva-Risso, Shuba Srinivasan and Dominique Hanssens (2004), "New products, sales promotions, and firm value: The case of the automobile industry," Journal of Marketing, 68 (4), 142-156.

Payne, Adrian and Pennie Frow (2005), "A Strategic Framework for Customer Relationship Management," Journal of Marketing, 69 (4), 167-176.

Pearlin, Leonard, Elizabeth Menaghan, Morton Lieberman and Joseph Mullan (1981), "The Stress Process," Journal of Health and Social Behavior, 22 (4), 337-356.

Pechmann, Cornelia, Elizabeth Moore, Alan Andreasen, Paul Connell, Dan Freeman, Meryl Gardner, Deborah Heisley, Craig Lefebvre, Dante Pirouz and Robin Soster (2011), 
"Navigating the Central Tensions in Research on At-Risk Consumers: Challenges and Opportunities," Journal of Public Policy \& Marketing, 30 (1), 23-30.

Ping, Robert (1994), "Does satisfaction moderate the association between alternative attractiveness and exit intention in a marketing channel?," Journal of the Academy of Marketing Science, 22 (4), 364-371.

Podsakoff, Philip, Scott MacKenzie, Jeong-Yeon Lee and Nathan Podsakoff (2003), "Common method biases in behavioral research: a critical review of the literature and recommended remedies," Journal of Applied Psychology, 88 (5), 879-903.

Pollai, Maria, Erik Hoelzl and Flavia Possas (2009), "Consumption-related emotions over time: Fit between prediction and experience," Marketing Letters, 21 (4), 1-15.

Preacher, Kristofer and Andrew Hayes (2008), "Asymptotic and resampling strategies for assessing and comparing indirect effects in multiple mediator models," Behavior Research Methods, 40 (3), 879-891.

Pressey, Andrew and Nikolaos Tzokas (2004), "Lighting up the "dark side" of international export/import relationships: Evidence from UK exporters," Management Decision, 42 (5), 694-708.

Raghunathan, Rajagopal and Julie Irwin (2001), "Walking the hedonic product treadmill: Default contrast and mood-based assimilation in judgments of predicted happiness with a target product," Journal of Consumer Research, 28 (3), 355-368.

Ratner, Rebecca, Barbara Kahn and Daniel Kahneman (1999), "Choosing less-preferred experiences for the sake of variety," Journal of Consumer Research, 26 (1), 1-15.

Reece, J. (1994), “The renewable myth: How companies get into trouble," Secured Lender, 50 (6), 50-54.

Reichheld, Frederick (1996), The Loyalty Effect: The Hidden Force Behind Growth, Profits, and Lasting Value. Boston: Harvard Business School Press.

Reinartz, Werner, Michael Haenlein and Joerg Henseler (2009), “An empirical comparison of the efficacy of covariance-based and variance-based SEM," International Journal of Research in Marketing, 26 (4), 332-344.

Reinartz, Werner, Manfred Krafft and Wayne Hoyer (2004), “The Customer Relationship Management Process: Its Measurement and Impcat on Performance," Journal of Marketing Research, 41 (August), 293-305. 
Reinartz, Werner and V. Kumar (2002), "The mismanagement of customer loyalty," Harvard Business Review, 80 (7), 86-95.

Romano, Pietro (2003), "Co-ordination and integration mechanisms to manage logistics processes across supply networks," Journal of Purchasing and Supply Management, 9 (3), $119-134$.

Rosenbaum, Paul and Donald Rubin (1983), "The central role of the propensity score in observational studies for causal effects," Biometrika, 70 (1), 41.

Rosenbaum, Paul and Donald Rubin (1984), "Reducing bias in observational studies using subclassification on the propensity score," Journal of the American Statistical Association, 79 (387), 516-524.

Rozanski, Horacio, Allen Baum and Bradley Wolfsen (1999), "Brand Zealots: Realizing the Full Value of Emotional Brand Loyalty,” Strategy and Business, 17 (Fourth Quarter), 51-62.

Ryals, Lynette (2005), "Making customer relationship management work: The measurement and profitable management of customer relationships," Journal of Marketing, 69 (4), 252-261.

Samaha, Stephen, Robert Palmatier and Rajiv Dant (2011), "Poisoning relationships: Perceived unfairness in channels of distribution," Journal of Marketing, 75 (3), 99-117.

Scheer, Lisa (2012), "Trust, distrust and confidence in B2B relationships," in Handbook of Business-to-Business Marketing, Gary Lilien, and Rajdeep Grewal, ed. Northampton, USA: Edward Elgar Publishing: 332.

Schmid, Jochen and Daniel Vogl (2003). Dell Computer Corporation - Best Practice for Relationship Marketing? Working Paper University of Albertay Dundee. 1-18.

Schwarz, Norbert and Jing Xu (2011), "Why don't we learn from poor choices? The consistency of expectation, choice, and memory clouds the lessons of experience," Journal of Consumer Psychology, 21 (2), 142-115.

Seligman, Martin, Tracy Steen, Nansook Park and Christopher Peterson (2005), "Positive psychology progress," American psychologist, 60 (5), 410-421.

Selnes, Fred and James Sallis (2003), "Promoting relationship learning," Journal of Marketing, 67 (3), 80-95. 
Shrout, Patrick and Niall Bolger (2002), "Mediation in experimental and nonexperimental studies: new procedures and recommendations," Psychological Methods; Psychological Methods, 7 (4), 422.

Silverman, Bernard (1986), Density estimation for statistics and data analysis. London: Chapman \& Hall.

Skinner, Steven, Jule Gassenheimer and Scott Kelley (1992), "Cooperation in supplier-dealer relations," Journal of Retailing, 68 (2), 174-193.

Slater, Stanley and John Narver (1994), "Does Competitive Environment Moderate the Market Orientation-Performance Relationship?," Journal of Marketing, 58 (1), 46-55.

Sloot, Laurent, Dennis Fok and Peter Verhoef (2006), "The short-and long-term impact of an assortment reduction on category sales," Journal of Marketing Research, 43 (4), 536-548.

Sobel, Michael (1987), "Direct and indirect effects in linear structural equation models," Sociological Methods \& Research, 16 (1), 155-176.

Sprott, David, Sandor Czellar and Eric Spangenberg (2009), "The importance of a general measure of brand engagement on market behavior: Development and validation of a scale," Journal of Marketing Research, 46 (1), 92-104.

Srinivasan, Raji and Christine Moorman (2005), "Strategic firm commitments and rewards for customer relationship management in online retailing," Journal of Marketing, 69 (4), 193200.

Stevens, Merieke, Matthias Holweg and Frits Pil (2012). Modulating between Relational and Contractual Approaches to Buyer Supplier Relations: A Case Study of Nissan Cambridge Judge Business School Working Papers.

Sun, Baohong, Shibo Li and Catherine Zhou (2006), “"Adaptive” learning and "proactive" customer relationship management," Journal of Interactive Marketing, 20 (3-4), 82-96.

Swaminathan, Anand (2006), "Framing interorganizational network change: a network inertia perspective," Academy of management review, 31 (3), 704-720.

Tähtinen, Jaana and Terje Vaaland (2006), "Business relationships facing the end: why restore them?," Journal of Business \& Industrial Marketing, 21 (1), 14-23.

Tenenhaus, Michel, Vincenzo Vinzi, Yves-Marie Chatelin and Carlo Lauro (2005), "PLS path modeling," Computational Statistics \& Data Analysis, 48 (1), 159-205. 
Terawatanavong, Civilai, Gregory Whitwell, Robert Widing and Aron O'Cass (2011), "Technological turbulence, supplier market orientation, and buyer satisfaction," Journal of Business Research, 64 (2011), 911-918.

Thibaut, John and Harold Kelley (1959), The Social Psychology of Groups. New York: John Wiley and Sons.

Trope, Yaacov and Nira Liberman (2010), "Construal-level theory of psychological distance," Psychological Review, 117 (2), 440.

Unilever (2012), "Long term supplier partnerships key to Unilever sustainable growth strategy," (accessed February 7, 2013), [available at http://www.unilever.com/mediacentre/pressreleases/2012/longtermsupplierpartnershipskey.as $\mathrm{px}]$.

Van Boven, Leaf (2005), "Experientialism, materialism, and the pursuit of happiness," Review of General Psychology, 9 (2), 132-142.

Verhoef, Peter (2003), "Understanding the Effect of Customer Relationship Management Efforts on Customer Retention and Customer Share Development," Journal of Marketing, 67 (October), 30-45.

Villena, Verónica, Elena Revilla and Thomas Choi (2011), "The dark side of buyer-supplier relationships: A social capital perspective," Journal of Operations Management, 29 (6), 561576.

Wang, Jing, Nathan Novemsky and Ravi Dhar (2009), "Anticipating Adaptation to Products," Journal of Consumer Research, 36 (2), 149-159.

Wangenheim, Florian v. and Tomás Bayón (2007), "Behavioral Consequences of Overbooking Service Capacity," Journal of Marketing, 71 (4), 36-47.

Wetzels, Martin, Gaby Odekerken-Schröder and Claudia Van Oppen (2009), "Using PLS path modeling for assessing hierarchical construct models: Guidelines and empirical illustration," MIS Quarterly, 33 (1), 177-195.

Wikipedia (2013), "Andrew Grove Quotes," (accessed January 25, 2013), [available at http://en.wikipedia.org/wiki/Andrew_Grove].

Williamson, Oliver (1985), The Economic Institutions of Capitalism. New York: The Free Press. 
Wooldridge, Jeffrey (2009), Introductory econometrics: A modern approach. Mason: SouthWestern Pub.

Wuyts, Stefan and Inge Geyskens (2005), "The formation of buyer-supplier relationships: Detailed contract drafting and close partner selection," Journal of Marketing, 69 (4), 103-117.

Yim, Chi , David Tse and Kimmy Chan (2008), "Strengthening customer loyalty through intimacy and passion: Roles of customer-firm affection and customer-staff relationships in services," Journal of Marketing Research, 45 (6), 741-756.

Yung, Yiu-Fai, David Thissen and Lori McLeod (1999), "On the relationship between the higher-order factor model and the hierarchical factor model," Psychometrika, 64 (2), 113-128.

Zablah, Alex, Danny Bellenger and Wesley Johnston (2004), “An evaluation of divergent perspectives on customer relationship management: Towards a common understanding of an emerging phenomenon," Industrial Marketing Management, 33 (6), 475-489.

Zetu, Dan, Jie Cheng, Michael Jay and Brigitte Lo (2003). When will a consumer consider buying another car? New Jersey, IEEE.

Zomerdijk, Leonieke and Christopher Voss (2010), "Service design for experience-centric services," Journal of Service Research, 13 (1), 67-82. 


\section{Summary}

\section{Combating the Dark Side: \\ Managing Performance Reinvigoration of Long-Term Relationships}

This dissertation elaborates upon the temporal development of long-term relationships. Our overarching proposition is that strong relationships predictably fade as time passes. Herein, two empirical studies provide theoretical and managerial insights on how to reinvigorate long-term relationships.

Study one tackles the fundamental question: Why do ongoing B2B relationships deliver progressively weaker returns over time? Based on a study among purchasing professionals, we posit that relationship slack is a result of buyer complacency - a state which is characterized by self-satisfaction with the status quo and excessive levels of trust, leading to sub-optimal monitoring of relationship performance. In turn, buyer complacency causes the emergence of other dark side symptoms which largely increase the attractiveness of alternative partnerships. To this end, we test a battery of strategies to prevent or combat these negative effects. Most notably, our findings indicate that joint goal-setting and periodic performance benchmarking help to re-invigorate relationship productivity.

In study two, we look at brand affect trajectories of automotive customers, as positive brand affect is a key component for establishing successful consumer-brand relationships. Unfortunately, consumers' emotional bonds to a brand may abate with time. Using survey and customer performance data from a longitudinal field experiment, we demonstrate that customers' brand affect follows a declining trajectory that erodes customer loyalty. However, planned customer experience actions can provide a suitable intervention mechanism for firms to mitigate this emotional decline. In fact, forestalling an emotional decline helps secure 
customer loyalty in advanced relationship stages. Specifically, firms should develop disrupted (high intensity) as opposed to continuous (low intensity) experience interventions to restore emotional bonds most effectively. Consequently, this thesis discovers hedonic adaptation processes as a dark side of consumer-brand relationships and suggests actionable levers to sustain customer loyalty. 


\section{Samenvatting}

\section{Combating the Dark Side:}

\section{Managing Performance Reinvigoration of Long-Term Relationship}

Deze dissertatie onderzoekt de continue ontwikkeling van lange-termijn relaties. De hoofdhypothese luidt dat sterke relaties op een voorspelbare wijze verzwakken bij het verstrijken van de tijd. Twee empirische studies leveren zowel theoretische als praktische inzichten voor het onderhouden van lange-termijn relaties.

Studie één onderzoekt de fundamentele vraag: Waarom laten B2B relaties vaak geleidelijk zwakkere resultaten zien na verloop van tijd? Gebaseerd op een studie met inkoopprofessionals stellen we dat het verzwakken van een relatie het resultaat is van de zelfgenoegzaamheid van klanten - een houding die wordt gekenmerkt door tevredenheid met de status quo alsmede excessief veel vertrouwen. Dit leidt ertoe dat de relatieprestatie minder in de gaten gehouden wordt. Daaropvolgend veroorzaakt de zelfgenoegzaamheid het ontstaan van andere, zogenaamde "dark side", symptomen die de aantrekkelijkheid van alternatieven verhogen. We testen een serie strategieën om deze negatieve effecten te voorkomen of te bestrijden. Onze bevindingen laten zien dat het gezamenlijk stellen van doelen alsmede het periodiek benchmarken van prestatie de productiviteit van de relatie helpt te onderhouden.

In studie twee kijken we naar de merkbinding van klanten in de auto-industrie, aangezien een positieve merkbinding een belangrijk onderdeel vormt voor het ontstaan van succesvolle klant-merk relaties. De emotionele binding met een merk van een consument kan jammer genoeg minder worden na verloop van tijd. Middels data uit vragenlijsten en klantprestaties van een lange-termijn veldexperiment laten we zien dat merkbinding een dalend verloop laat zien en daardoor klantloyaliteit flink aantast. Echter, geplande acties, gericht op het creëren van positieve klantervaringen, kunnen voor bedrijven een gepast 
interventie-mechanisme vormen om deze dip in de affectieve merkbinding tegen te gaan. Feitelijk kan het voorkomen van deze emotionele daling helpen de klantloyaliteit te behouden in vergevorderde stadia van een relatie. Voor bedrijven betekent dit dat het toepassen van verstoorde (hoge intensiteit) belevenisinterventies effectiever is dan het toepassen van doorlopende (lage intensiteit) belevenisinterventies. Zodoende laat deze thesis zien dat zogenaamde hedonische aanpassingsprocessen onderdeel vormen van de donkere zijde van klant-merk relaties en geeft praktische tips om klantloyaliteit te onderhouden. 